\title{
Post-Synthetic Modification of DNA Phosphodiester Backbone for Photocaged DNAzyme
}

\author{
Xiaoyan Wang, ${ }^{\ddagger}$ Mengli Feng, ${ }^{\ddagger}$ Lu Xiao, Aijun Tong, Yu Xiang ${ }^{*}$ \\ Department of Chemistry, Beijing Key Laboratory for Microanalytical Methods and Instrumentation, Key \\ Laboratory of Bioorganic Phosphorus Chemistry and Chemical Biology (Ministry of Education), Tsinghua \\ University, Beijing 100084, China. \\ E-mail: xiang-yu@tsinghua.edu.cn \\ Tel: +86-10-62782759 \\ Fax: +86-10-62782485
}

\section{Table of content}

1. Materials and Instrument

2. Synthesis

3. Experimental Procedures

3. Additional Figures (Figure S1-S15)
Page S-2

Page S-3

Page S-4

Page S-5 


\section{Materials and Instrument}

The chemical 2-bromo-4'-hydroxyacetophenone was purchased from either Tokyo Chemical Industry Development Co., Ltd. (Shanghai, China) or Sigma-Aldrich (Shanghai, China) and used as received. The two batches gave the same results of modification. Lipofectamine 2000 was from Thermo Fisher Scientific Inc. (MA, USA). Acrylamide, N,N'-methylene diacrylamide, ammonium persulphate, urea, 2-bromo-4'-nitroacetophenone and potassium diethylthiophosphate were bought from Sigma-Aldrich (Shanghai, China). N,N-Dimethylformamide (DMF), sodium dihydrogen phosphate dehydrate and other reagents for synthesis were from Sinopharm Chemical Reagent Beijing Co. (Beijing, China). Zinc nitrate hexahydrate, magnesium chloride hexahydrate, 3-morpholinopropanesulfoinc acid (MOPS), sucrose, Tris(hydroxymethyl)aminomethane (Tris) were purchased from Alfa Aesar (Tianjin, China). Dulbecco's modified Eagle's medium (DMEM), Dulbecco's Phosphate Buffered Saline (DPBS), Opti-MEM medium, fetal bovine serum (FBS), $100 \mathrm{IU} / \mathrm{mL}$ penicillin-streptomycin and $0.25 \%$ Trypsin were purchased from Corning cellgro (NY, USA). RIPA lysis buffer was from Biomiga (Shanghai, China). HeLa cells were purchased from National Platform of Experimental Cell Resources for Sci-Tech (Beijing, China).

Oligonucleotides were synthesized and purified by either Integrated DNA Technologies, Inc. (IA, USA) or Sangon Biotech Co., Ltd. (Shanghai, China) with the following sequences and modifications (from left to right, 5' to 3'. The base with a "*”" indicates a phosphorothioate at the 3 ' of the nucleotide. The FAM at 5' end is a fluorescein modification. Those at 3' end are all quenchers: IABkFQ is Iowa Black® FQ, Dab is Dabcyl and BHQ1 is Black Hole Quencher®-1. Dithiol is a modification used to protect 5' end of DNA against cellular nucleases. Underlined $\mathrm{rA}$ or $\mathrm{rG}$ is a ribonucleotide, which is essential for the DNAzyme-catalyzed cleavage.

T15-1PS: TTTTTTTT*TTTTTTT

8-17 DNAzyme: CATCTCTTCTCCGAGCCGGTCGAAATAGTGAGT

8-17-1PS: CATCTCTTCTCCG*AGCCGGTCGAAATAGTGAGT

8-17-3PS: CATCTCTTCTCCG*A*G*CCGGTCGAAATAGTGAGT

F-8-17 substrate (for PAGE): FAM-ACTCACTATrAGGAAGAGATG

F-8-17-Q substrate (for fluorescence kinetics): FAM-ACTCACTATrAGGAAGAGATG-IABkFQ

10-23: AGGACGGGAGGCTAGCTACAACGAGTGGTTGCC

10-23-1PS: AGGACGGGAGGC*TAGCTACAACGAGTGGTTGCC

10-23-3PS: AGGACGGGAGGC*T*A*GCTACAACGAGTGGTTGCC

F-10-23-Q substrate: FAM-GGCAACCACrGTCCCGTCCT-IABkFQ

Dually labelled 8-17-3PS (for HeLa cells):

Dithiol-CACGTCCATCTCTTCTCCG*A*G*CCGGTCGAAATAGTGAGT-Dab

F-8-17-Q substrate long (for HeLa cells):

FAM-ACTCACTATrAGGAAGAGATGGACGTG-3-BHQ1

Buffer for 8-17 DNAzymes: 0.5 mM Zn(NO$)_{2}, 100 \mathrm{mM} \mathrm{NaCl}, 100 \mathrm{mM}$ MOPS, pH 7.0.

Buffer for 10-23 DNAzymes: $10 \mathrm{mM} \mathrm{MgCl}_{2}, 150 \mathrm{mM} \mathrm{NaCl}, 50 \mathrm{mM}$ Tris-HCl, pH 7.5.

${ }^{1} \mathrm{H},{ }^{13} \mathrm{C}$ and ${ }^{31} \mathrm{P}$ NMR spectra were recorded on a JOEL JNM-ECA 300 spectrometer (Tokyo, Japan). Mass spectra were obtained on a SHIMADZU LCMS-IT-TOF liquid chromatograph mass spectrometer or a SHIMADZU MALDI-TOF mass spectrometer (Kyoto, Japan). Fluorescence spectra were taken on a JASCO FP-6500 fluorometer (Tokyo, Japan). UV-Vis spectra were recorded by a JASCO V-550 UV-VIS spectrophotometer. Fluorescence cell imaging was operated on an OLYMPUS FV1000 confocal (Tokyo, Japan), with a laser scanning microscopy using 40X lens and 20X lens, and an NIKON A1RMPSi laser scanning confocal microscope (Tokyo, Japan) using 100X oil lens. X-ray crystal data was collected on a BRUKER P4 X-ray single crystal diffactometor (Madison, USA), and the single crystal was obtained by 
slow evaporation of a saturated solution in ethanol. UV irradiation was applied using a $12 \mathrm{~W}$ commercial handheld UV lamp at $365 \mathrm{~nm}$ (with a filter to remove light $<365 \mathrm{~nm}$ to minimize damage to DNA) with a sample-to-lamp distance of $5 \mathrm{~cm}$ for in vitro studies, while for cellular studies the distance was increased to about $8 \mathrm{~cm}$ because of the microscope instrument setup. Gaussian calculation was carried out using B3LYP/6-31G(d,p).

\section{Synthesis}

\section{(1) Synthesis of DEPT-OH}

To a solution of $0.44 \mathrm{~g}(2.1 \mathrm{mmol})$ potassium diethylthiophosphate dissolved in $50 \mathrm{~mL}$ acetonitrile was gradually added $0.43 \mathrm{~g}$ ( $2 \mathrm{mmol})$ 2-bromo-4'-hydroxyacetophenone. The mixture was allowed to stand at room temperature with stirring for $15 \mathrm{~min}$. The complete of reaction can be monitored by TLC using ethyl acetate vs. petroleum ether $=1: 1(\mathrm{v} / \mathrm{v})$. After that, the solvent was removed under reduced pressure, and the residue was treated with $50 \mathrm{~mL}$ ethyl acetate and $50 \mathrm{~mL}$ water. The organic later was collected and washed by $50 \mathrm{~mL}$ water for three times, and then dried by anhydrous $\mathrm{Na}_{2} \mathrm{SO}_{4}$. After evaporating the solvent under reduced pressure, DEPT-OH was obtained as a white powder $(0.54 \mathrm{~g}$, yield $89 \%) .{ }^{1} \mathrm{H}$ NMR $(300 \mathrm{MHz}$, DMSO-d $), \delta(\mathrm{ppm}): 11.52(\mathrm{~s}, 1 \mathrm{H}), 7.88(\mathrm{~d}, 2 \mathrm{H}), 6.87(\mathrm{~d}, 2 \mathrm{H}), 4.45(\mathrm{~s}, 1 \mathrm{H}), 4.40(\mathrm{~s}, 1 \mathrm{H}), 4.08(\mathrm{q}, 4 \mathrm{H}), 1.23$ (t, 6H). ${ }^{13} \mathrm{C}-\mathrm{NMR}$ (300 MHz, DMSO-d $), \delta$ (ppm): 191.9, 163.1, 131.6, 127.1, 115.9, 63.8, 37.9, 16.3. LCMS-IT-TOF spectrometry: calc. for $\mathrm{C}_{12} \mathrm{H}_{17} \mathrm{O}_{5} \mathrm{PS},[\mathrm{M}-\mathrm{H}]^{-}$303.3, found 303.0.

\section{(2) Synthesis of TEEP-OH}

To a solution of $0.42 \mathrm{~g}(2 \mathrm{mmol})$ potassium diethylthiophosphate dissolved in $50 \mathrm{~mL}$ acetonitrile was added $0.86 \mathrm{~g}$ (4 mmol) 2-bromo-4'-hydroxyacetophenone and $1.38 \mathrm{~g}$ (10 mmol) $\mathrm{K}_{2} \mathrm{CO}_{3}$. The mixture was allowed to stand at room temperature with stirring for $3 \mathrm{~h}$. The complete of reaction can be monitored by TLC using ethyl acetate vs. petroleum ether $=2: 1(\mathrm{v} / \mathrm{v})$. After that, the solvent was removed under reduced pressure, and the residue was treated with $50 \mathrm{~mL}$ ethyl acetate and $50 \mathrm{~mL}$ water. The organic later was collected and washed by $50 \mathrm{~mL}$ water for three times, and then dried by anhydrous $\mathrm{Na}_{2} \mathrm{SO}_{4}$. After evaporating the solvent under reduced pressure, TEEP-OH was obtained as a light yellow powder $(0.81 \mathrm{~g}$, yield 92\%). ${ }^{1} \mathrm{H}$ NMR (300 MHz, DMSO-d 6 ), $\delta(\mathrm{ppm}): 10.45$ (s, 1H), $9.69(\mathrm{~s}, 1 \mathrm{H}), 7.91(\mathrm{~d}, 2 \mathrm{H}), 7.29(\mathrm{~d}, 2 \mathrm{H})$, $6.87(\mathrm{~d}, 2 \mathrm{H}), 6.76(\mathrm{~d}, 2 \mathrm{H}), 6.30(\mathrm{~s}, 1 \mathrm{H}), 4.28(\mathrm{~s}, 2 \mathrm{H}), 4.03(\mathrm{q}, 4 \mathrm{H}), 1.17(\mathrm{t}, 6 \mathrm{H}),{ }^{13} \mathrm{C}-\mathrm{NMR}(300 \mathrm{MHz}$, $\left.\mathrm{CD}_{3} \mathrm{CN}\right), \delta$ (ppm): 192.8, 162.0, 157.6, 145.2, 131.3, 127.6, 126.7, 126.4, 115.4, 115.3, 109.9, 64.8, 39.0, 15.4. LCMS-IT-TOF spectrometry: calc. for $\mathrm{C}_{20} \mathrm{H}_{23} \mathrm{O}_{7} \mathrm{PS}[\mathrm{M}+\mathrm{Na}]^{+} 461.4$, found 461.1 .

\section{(3) Synthesis of TEEP-NO}

To a solution of $0.42 \mathrm{~g}(2 \mathrm{mmol})$ potassium diethylthiophosphate dissolved in $50 \mathrm{~mL}$ acetonitrile was added $0.98 \mathrm{~g}$ (4 mmol) 2-bromo-4'-nitroacetophenone and $1.38 \mathrm{~g}(10 \mathrm{mmol}) \mathrm{K}_{2} \mathrm{CO}_{3}$. The mixture was allowed to stand at room temperature with stirring for $2 \mathrm{~h}$. The complete of reaction can be monitored by TLC using ethyl acetate vs. petroleum ether $=2: 1(\mathrm{v} / \mathrm{v})$. After that, the solvent was removed under reduced pressure, and the residue was treated with $50 \mathrm{~mL}$ ethyl acetate and $50 \mathrm{~mL}$ water. The organic later was collected and washed by $50 \mathrm{~mL}$ water for three times, and then dried by anhydrous $\mathrm{Na}_{2} \mathrm{SO}_{4}$. After evaporating the solvent under reduced pressure, TEEP-NO $\mathbf{2}_{2}$ was obtained as a yellow powder $(0.94 \mathrm{~g}$, yield 95\%). ${ }^{1} \mathrm{H}$ NMR (300 MHz, DMSO-d 6 ), $\delta(\mathrm{ppm}): 8.38(\mathrm{~d}, 2 \mathrm{H}), 8.27(\mathrm{~d}, 2 \mathrm{H}), 8.24(\mathrm{~d}, 2 \mathrm{H}), 7.70(\mathrm{~d}, 2 \mathrm{H}), 7.17$ $(\mathrm{s}, 1 \mathrm{H}), 4.71(\mathrm{~s}, 2 \mathrm{H}), 4.10(\mathrm{q}, 4 \mathrm{H}), 1.22(\mathrm{t}, 6 \mathrm{H}) .{ }^{13} \mathrm{C}-\mathrm{NMR}$ (300 MHz, DMSO-d $), \delta(\mathrm{ppm}): 193.7,150.6$, 146.9, 141.3, 141.2, 140.6, 140.5, 130.4, 125.5, 124.4, 120.7, 65.2, 41.0, 16.4. LCMS-IT-TOF spectrometry: calc. for $\mathrm{C}_{20} \mathrm{H}_{21} \mathrm{~N}_{2} \mathrm{O}_{9} \mathrm{PS}[\mathrm{M}+\mathrm{Na}]^{+} 519.4$, found 519.1 .

\section{(4) Synthesis of TEEP-OH-modified DNA and DNAzymes}

A $30 \mu \mathrm{L}$ solution of $333 \mathrm{nM}$ DNA or DNAzymes containing phosphorothioates in $100 \mathrm{mM}$ sodium phosphate at $\mathrm{pH} 6.0$ was added $10 \mu \mathrm{L} 40 \mathrm{mM}$ 2-bromo-4'-hydroxyacetophenoe in DMF. The solution was kept on a roller at $37^{\circ} \mathrm{C}$ for $6 \mathrm{~h}$ and $20 \mathrm{~h}$ for 1PS and 3PS DNA, respective. The resulting solution was 
purified by Amicon-3K ultrafilters using DNAzyme buffers without cofactors to remove excess 2-bromo-4'-hydroxyacetophenoe for 6 times (or water to remove salts for MALDI-TOF analysis).

\section{Experimental Procedures}

(1) Fluorescence measurement of the kinetics of 8-17 DNAzymes in cleaving the labelled substrate

The test solution contained $50 \mathrm{nM}$ one of 8-17 DNAzymes and $250 \mathrm{nM} \mathrm{F-8-17-Q} \mathrm{substrate} \mathrm{in} 100 \mathrm{mM}$ $\mathrm{NaCl}, 100 \mathrm{mM}$ MOPS, $\mathrm{pH}$ 7.0. UV light irradiation at $365 \mathrm{~nm}$ for $15 \mathrm{~min}$ was applied to the DNAzymes prior to the experiment if necessary. To start the reaction, $\mathrm{Zn}^{2+}$ was added to a final concentration of $0.5 \mathrm{mM}$ with vortexing. The solution was then immediately measured by a fluorometer for the fluorescence intensity (excitation/emission $=490 / 520 \mathrm{~nm}$ ). The measurement was carried out at $25^{\circ} \mathrm{C}$

(2) Fluorescence measurement of the kinetics of 10-23 DNAzymes in cleaving the labelled substrate

The test solution contained $37.5 \mathrm{nM}$ one of 10-23 DNAzymes and $250 \mathrm{nM}$ F-8-17-Q substrate in 100 $\mathrm{mM} \mathrm{NaCl}, 100 \mathrm{mM}$ MOPS, $\mathrm{pH}$ 7.0. UV light irradiation at $365 \mathrm{~nm}$ for $15 \mathrm{~min}$ was applied to the DNAzymes prior to the experiment if necessary. To start the reaction, $\mathrm{Mg}^{2+}$ was added to a final concentration of $10 \mathrm{mM}$ with vortexing. The solution was then immediately measured by a fluorometer for the fluorescence intensity (excitation/emission $=490 / 520 \mathrm{~nm}$ ). The measurement was carried out at $37^{\circ} \mathrm{C}$

(3) PAGE imaging of TEEP-OH-modified DNAzymes

A solution of $10 \mu \mathrm{L}$ each DNA sample with or with TEEP-OH modifications in DNAzyme buffers without cofactors was mixed with $10 \mu \mathrm{L}$ loading buffer containing $1 \mathrm{M}$ sucrose and $6 \mathrm{M}$ urea. UV light irradiation at $365 \mathrm{~nm}$ for $15 \mathrm{~min}$ was applied to the DNAzymes prior to the experiment if necessary. Each solution was loaded to one lane of a $20 \%$ denatured polyacrylamide gels for PAGE analysis.

(4) PAGE imaging of the kinetics of 8-17 DNAzymes in cleaving the labelled substrate

A solution of $50 \mathrm{nM}$ 8-17 DNAzyme (photocaged or not) in $100 \mathrm{mM} \mathrm{NaCl}, 100 \mathrm{mM}$ MOPS, pH 7.0 was applied UV irradiation at $365 \mathrm{~nm}$ for $15 \mathrm{~min}$ if necessary. The solution was added $250 \mathrm{nM} \mathrm{F-8-17}$

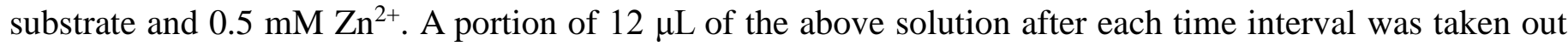
and added $0.8 \mathrm{mM}$ EDTA to stop the reaction, followed by the addition of $12 \mu \mathrm{L}$ loading buffer containing 1 M sucrose and $6 \mathrm{M}$ urea. Samples were loaded to a $20 \%$ denatured polyacrylamide gels for PAGE analysis.

(5) HeLa cell lysates for DNAzyme activity measurement

About $5 \times 10^{6}$ Hela cells were treated by trypsin for about $2 \mathrm{~min}$. Cells were precipitated by centrifugation (12000 rpm for $2 \mathrm{~min}$ ) and washed thoroughly with water for 3 times. The cell pellet was added $200 \mu \mathrm{L}$ RIPA lysis buffer and kept on a roller for $30 \mathrm{~min}$ at room temperature. After centrifugation (12000 rpm for $5 \mathrm{~min}$ ), the supernatant was recovered as the cell lysate. The cell lysate was diluted for 20-fold by DNAzyme buffers to make the solution clear for fluorescence kinetics measurement.

(6) Fluorescence imaging of DNAzyme activity in live HeLa cells

Two dishes of Hela cells were grown on a culture plate in DMEM, supplemented with 10\% FBS and $1 \%$ $100 \mathrm{IU} / \mathrm{mL}$ penicillin-streptomycin. Cells were kept in a $\mathrm{CO} 2$ incubator with a humidified atmosphere containing $5 \% \mathrm{CO}_{2}$ at $37{ }^{\circ} \mathrm{C}$. On the day of experiments, DMEM medium was removed and washed with Opti-MEM for 3 times, and added $0.8 \mathrm{~mL}$ Opti-MEM medium for $1 \mathrm{~h}$ before the addition of $200 \mu \mathrm{L}$ Lipo-DNA mixture containing $4 \mu \mathrm{L}$ Lipofectamine 2000, $100 \mathrm{nM}$ 3-TEEP-OH-modified 8-17 DNAzyme (dually labelled) and $20 \mathrm{nM}$ "F-8-17-Q substrate long". The cells were co-incubated with the Lipo-DNA for $4 \mathrm{~h}$ and then washed with DMEM for 3 times. One dish of the cells was directly imaged under the confocal

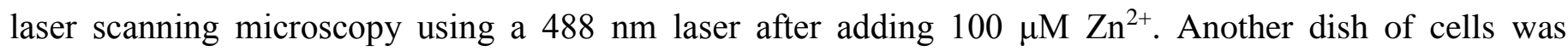
irradiated at $365 \mathrm{~nm}$ for $20 \mathrm{~min}$, and then added $100 \mu \mathrm{M} \mathrm{Zn}^{2+}$. The fluorescence images at each time interval were recorded by a confocal microscopy. The emission signal was collected in the wavelength range of 500-600 nm. 


\section{Additional Figures}

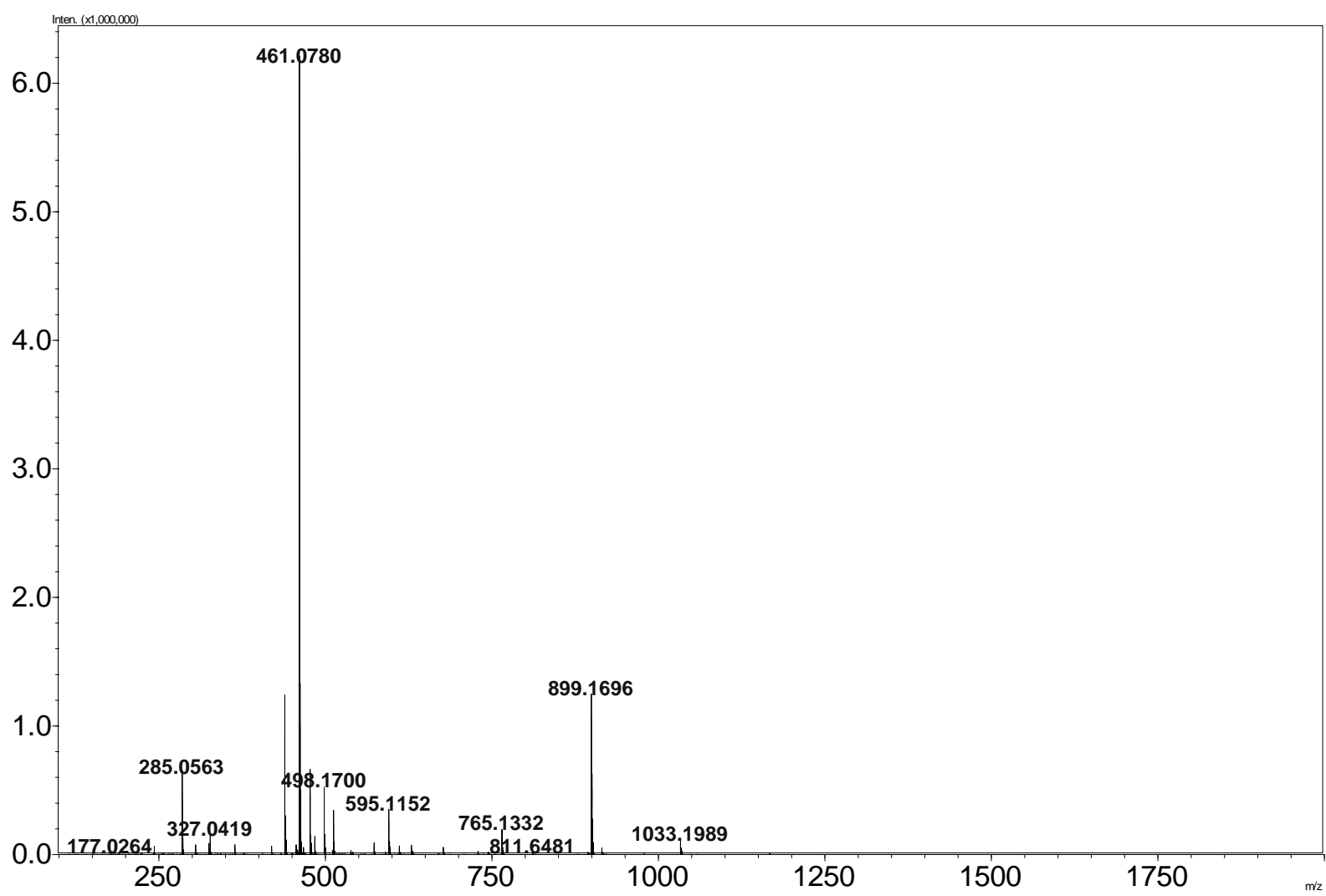

Figure S1a. ESI-MS $\left([\mathrm{M}+\mathrm{Na}]^{+}=461.1,[2 \mathrm{M}+\mathrm{Na}]^{+}=899.2\right)$ spectrum of TEEP-OH $($ calc. $\mathrm{M}=438.4)$. 


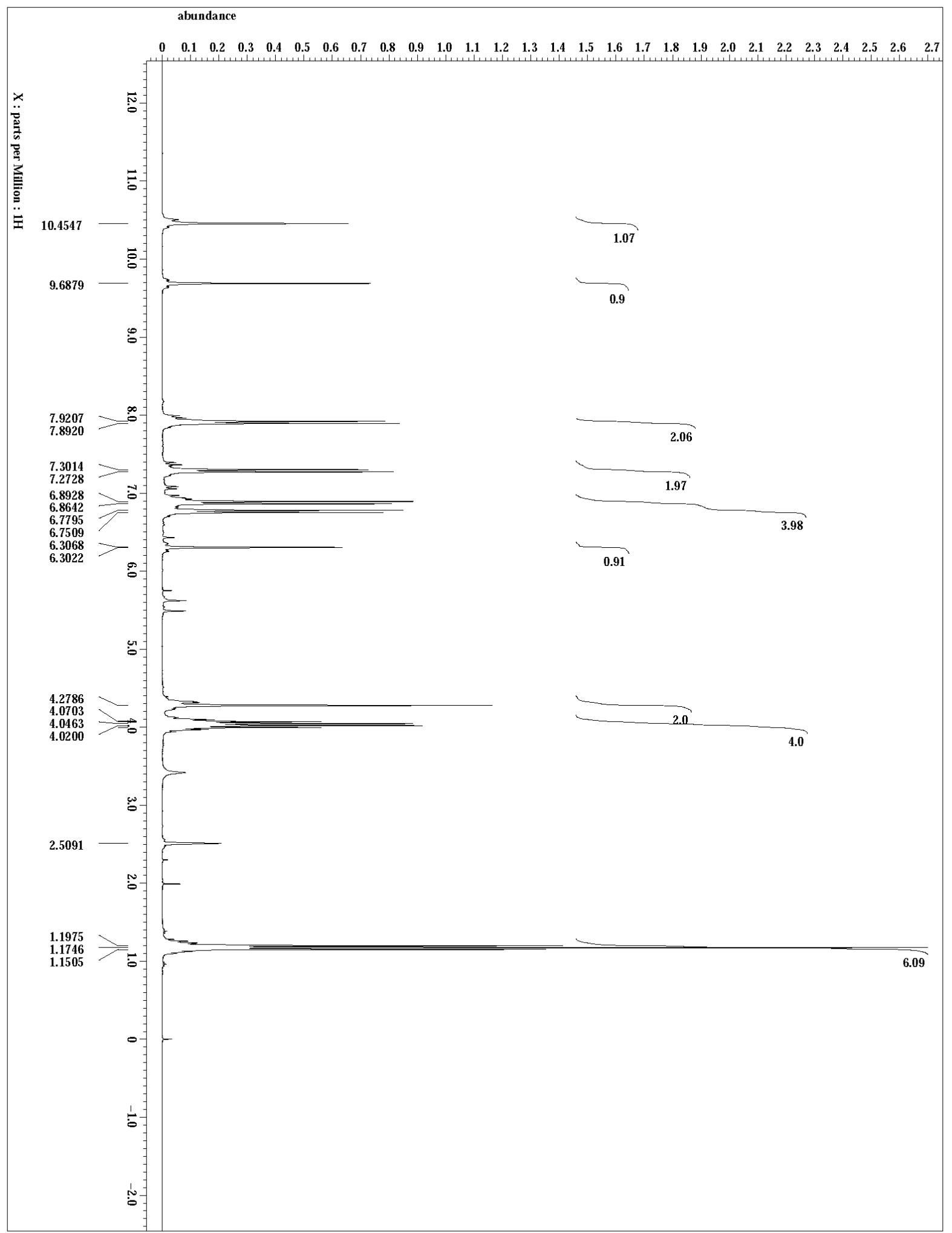

Figure S1b. ${ }^{1} \mathrm{H}-\mathrm{NMR}\left(\mathrm{DMSO}^{-} \mathrm{d}_{6}\right)$ spectra of TEEP-OH. 


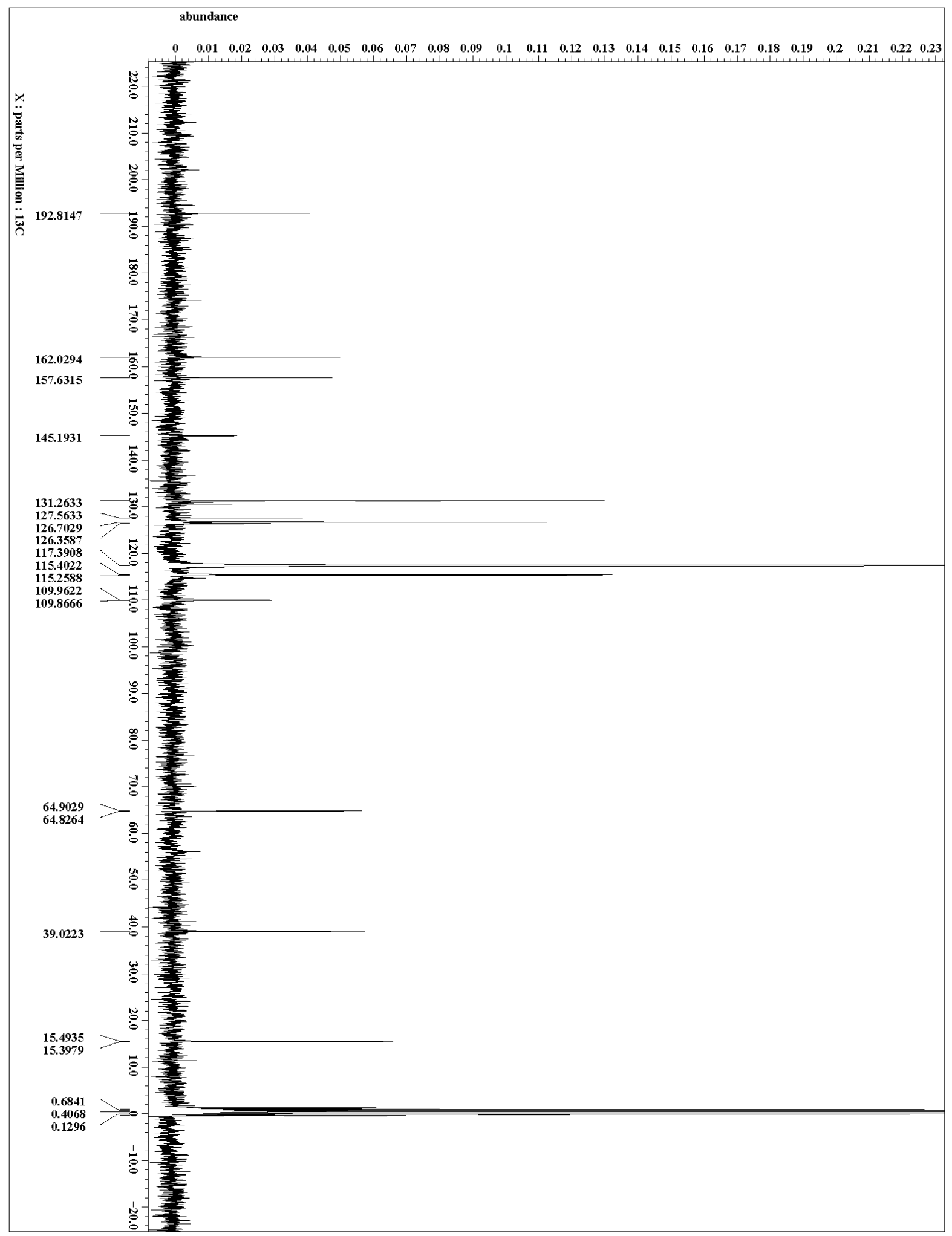

Figure S1c. ${ }^{13} \mathrm{C}-\mathrm{NMR}\left(\mathrm{CD}_{3} \mathrm{CN}-\mathrm{d}_{3}\right)$ spectra of TEEP-OH. 

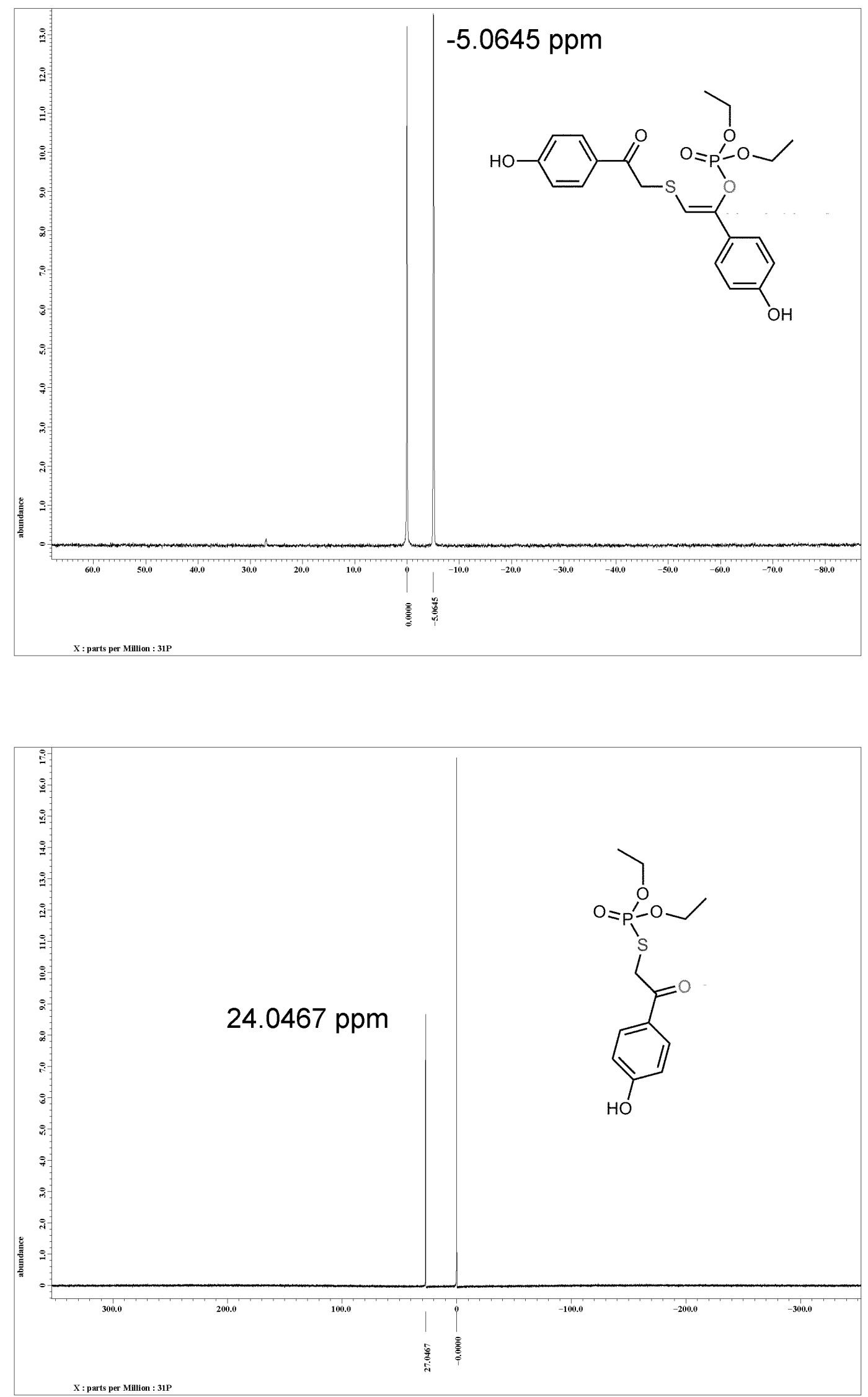

Page S-8 


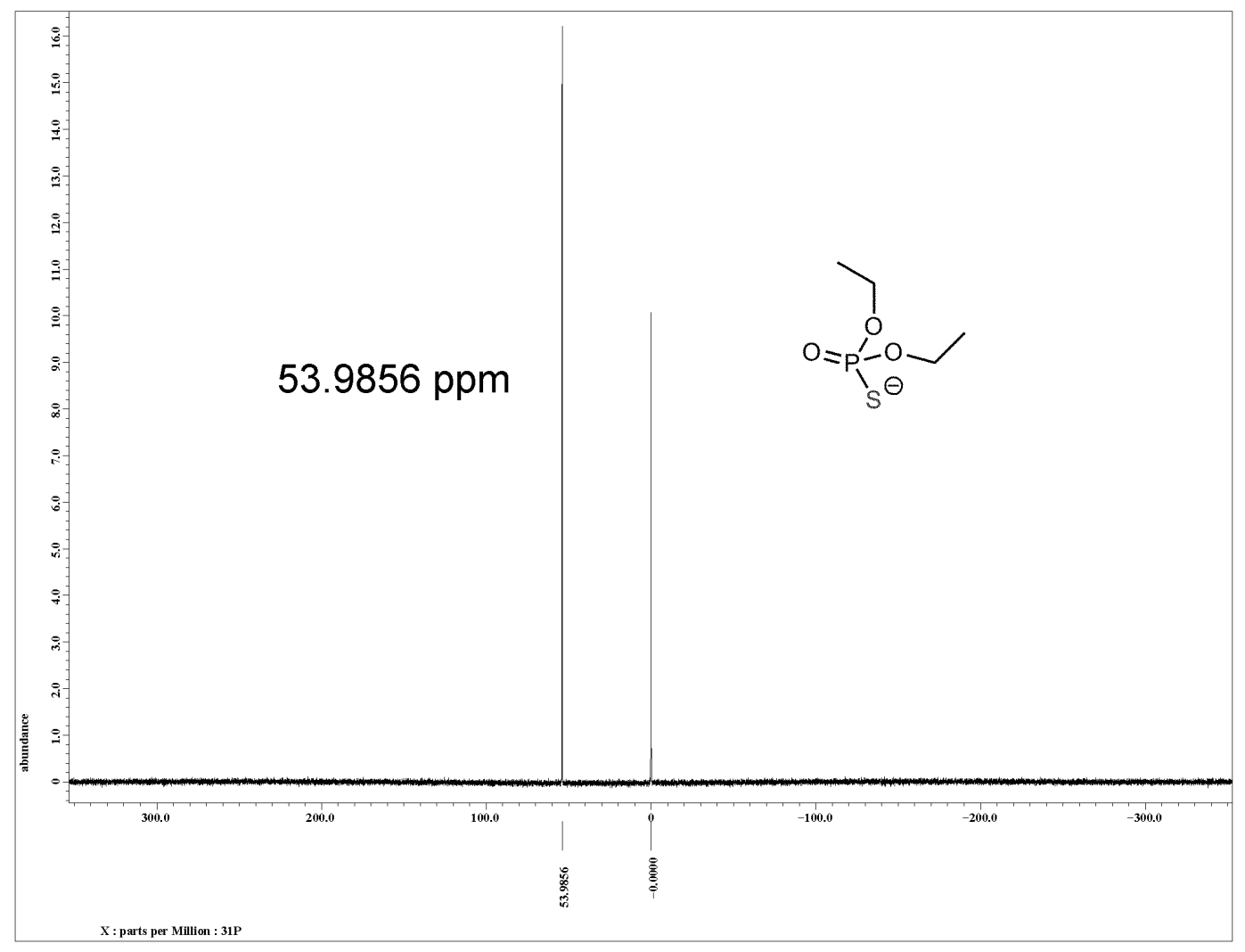

Figure S2. ${ }^{31} \mathrm{P}-\mathrm{NMR}$ (DMSO- $\mathrm{d}_{6}, \mathrm{H}_{3} \mathrm{PO}_{4}$ as 0 ppm standard) spectra of TEEP-OH, DEPT-OH and diethylthiophosphate.

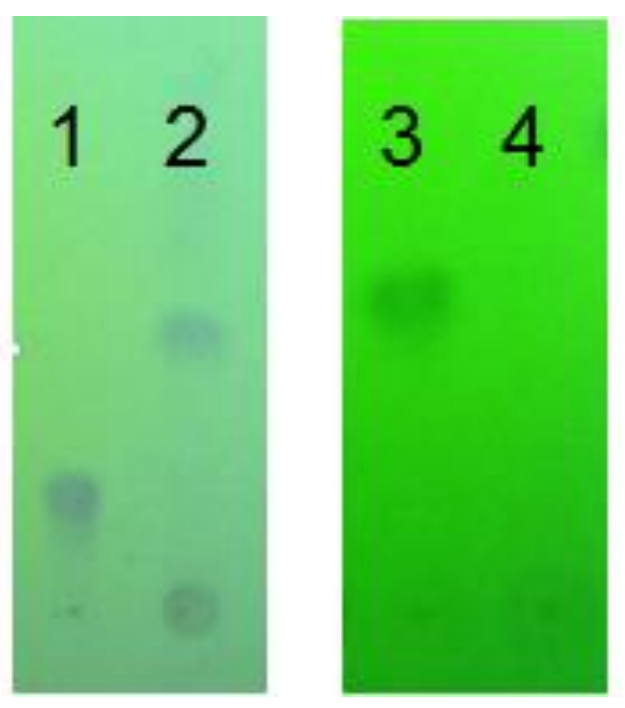

Figure S3. TLC (ethyl acetate and petroleum ether = 1:1, v/v) images of $1 \mathrm{mM}$ TEEP-OH (lane 1 and 2) and DEPT-OH (3 and 4) in $\mathrm{CH}_{3} \mathrm{CN}$ before (1 and 3) and after (2 and 4) UV irradiation for 30 min, indicating the completion of photolysis. 


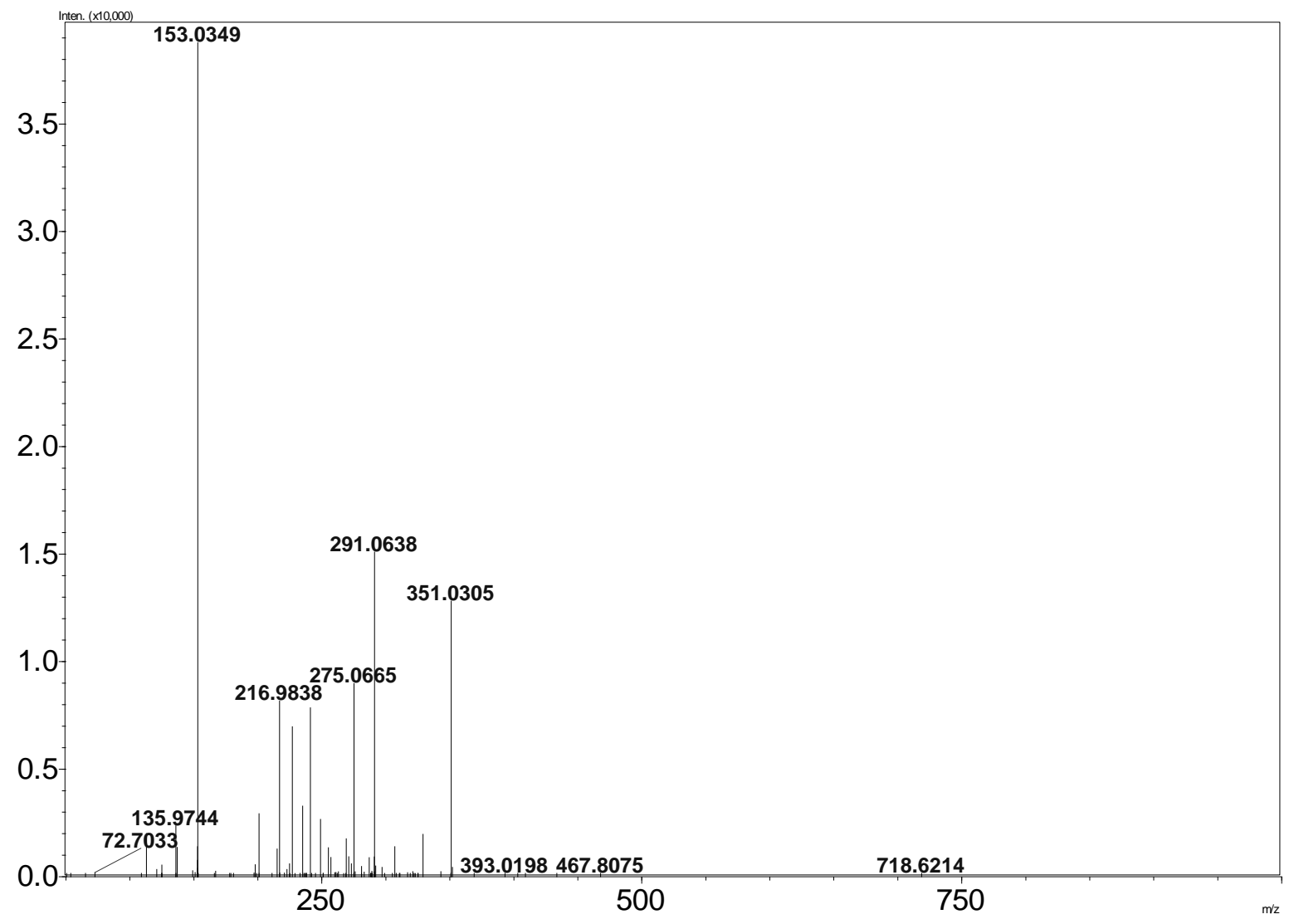

Figure S4a. ESI-MS (negative ion) spectrum of $1 \mathrm{mM}$ TEEP-OH in $\mathrm{CH}_{3} \mathrm{CN}$ after UV irradiation for 30 $\min$. The peak $\mathrm{m} / \mathrm{z}=153.0$ indicates the formation of diethylphosphate instead of diethylthiophosphate.

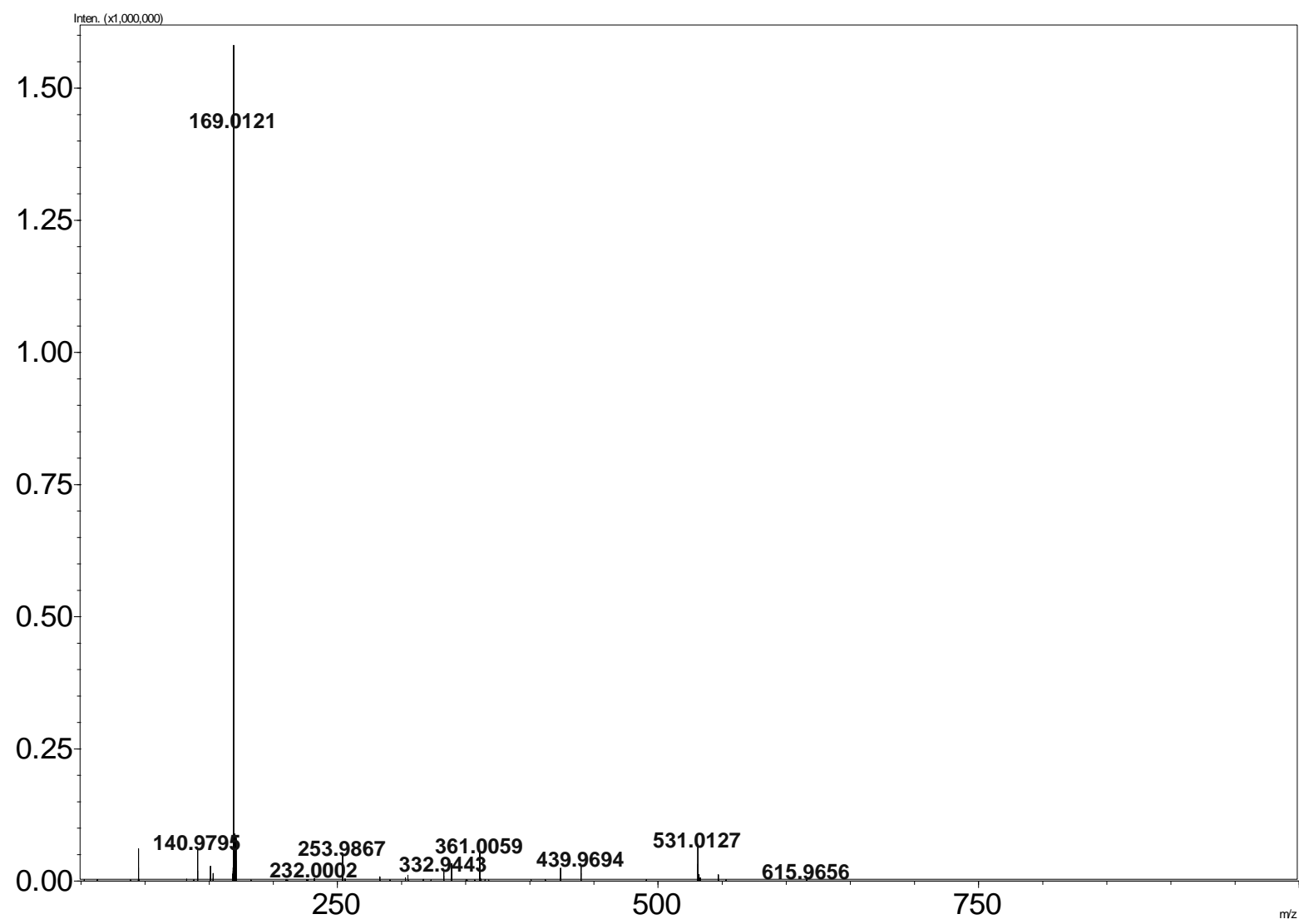

Figure S4b. ESI-MS (negative ion) spectrum of $1 \mathrm{mM}$ DEPT-OH in $\mathrm{CH}_{3} \mathrm{CN}$ after UV irradiation for 30 $\min$. The peak $m / z=169.0$ indicates the formation of diethylthiophosphate instead of diethylphosphate. 

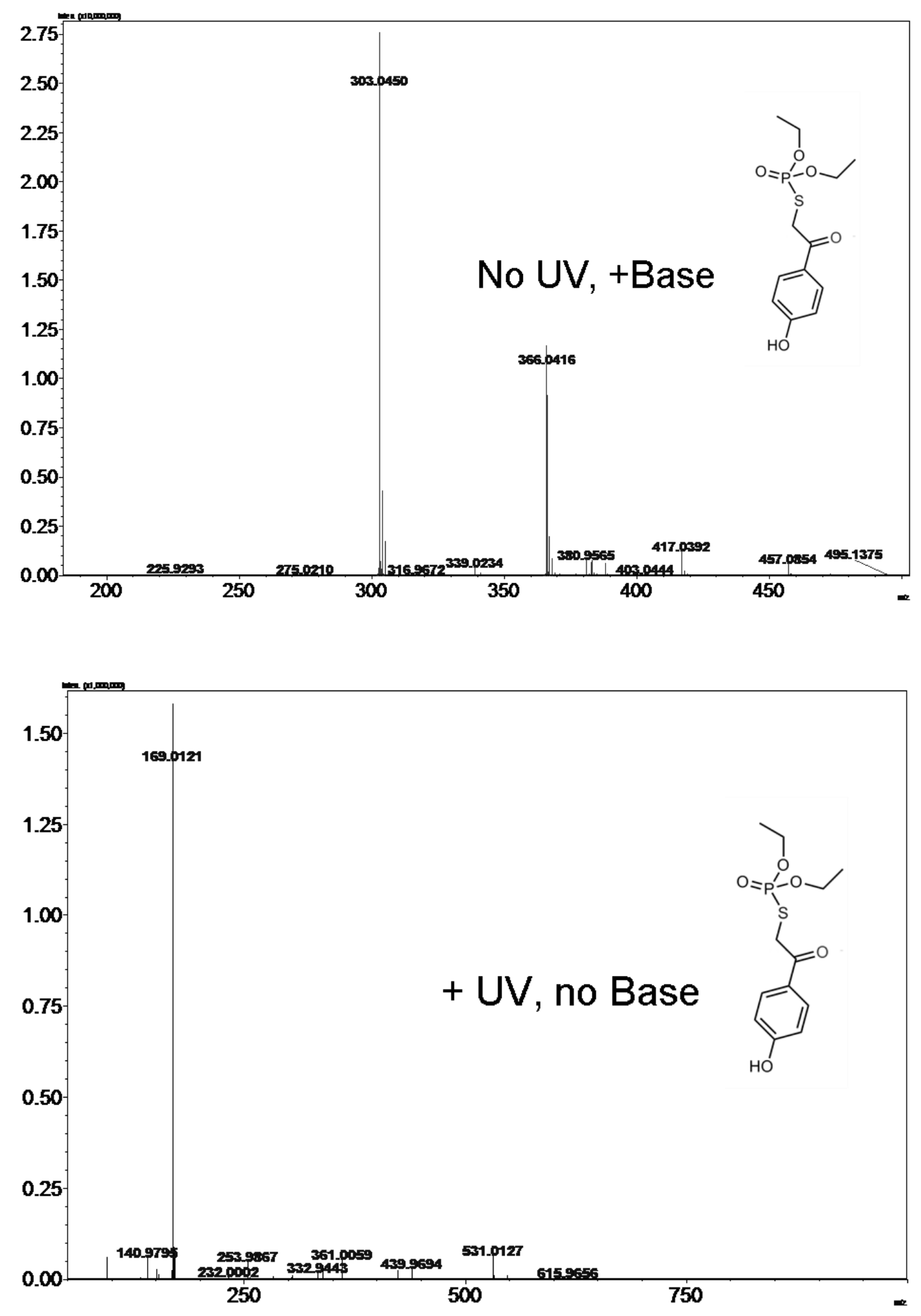


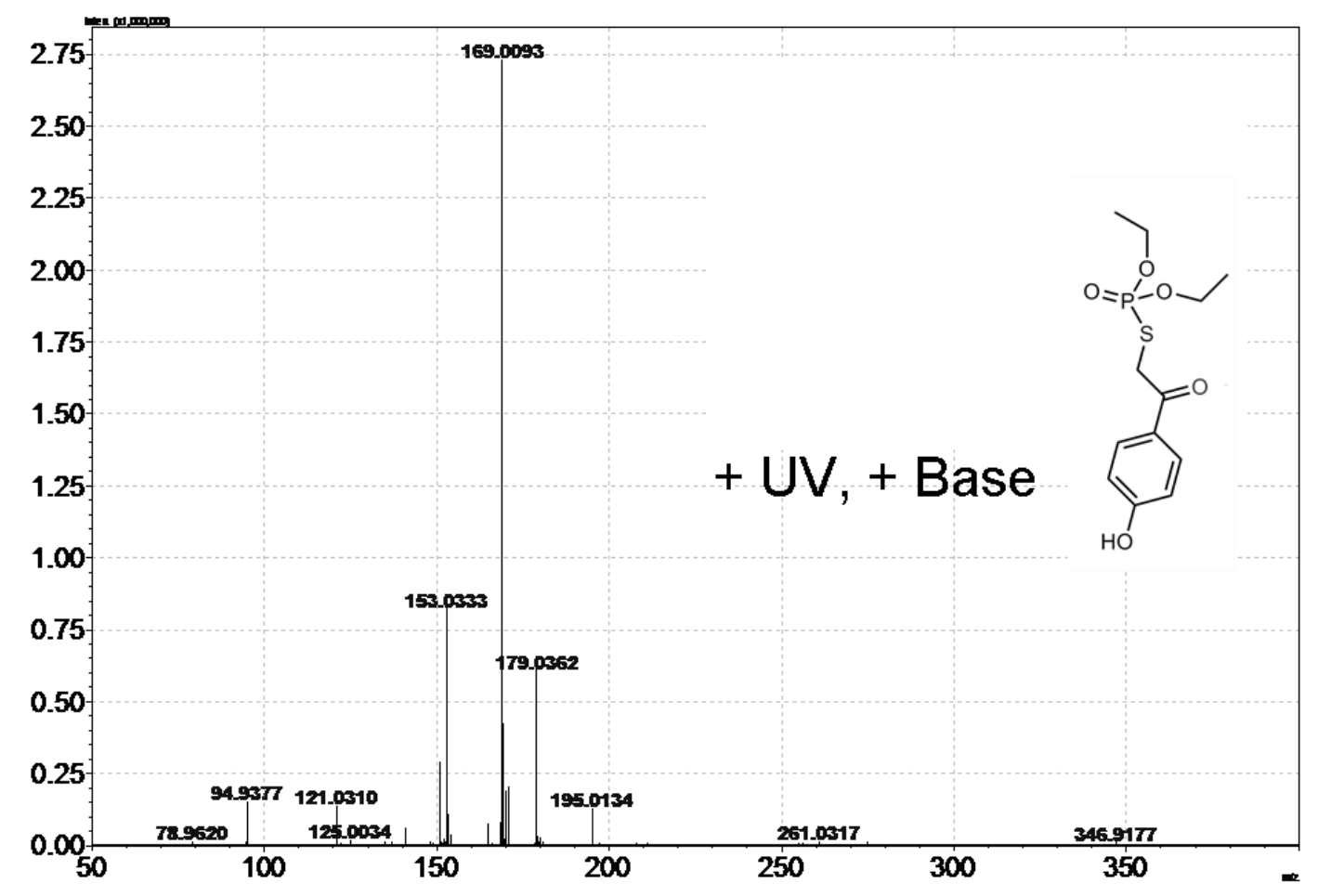

Figure S5. ESI-MS (negative ion) spectrum of $1 \mathrm{mM}$ DEPT-OH (calc. M = 304.3) before (top, [DEPT-O] ${ }^{-}$ = 303.0) and after UV irradiation for $30 \mathrm{~min}$ in $\mathrm{CH}_{3} \mathrm{CN}$ without base (middle, [diethylthiophosphate] ${ }^{-}=$ 169.0) or with base $\mathrm{Cs}_{2} \mathrm{CO}_{3}$ (bottom, [diethylthiophosphate] ${ }^{-}=169.0$ and [diethylphosphate] ${ }^{-}=153.0$ ). The formation of some diethylphosphate by photolysis in the presence of base suggests basic condition may allow DEPT-OH partially transformed into PTET, which is converted into diethylphosphate only after UV irradiation. 
(a) Neutral form
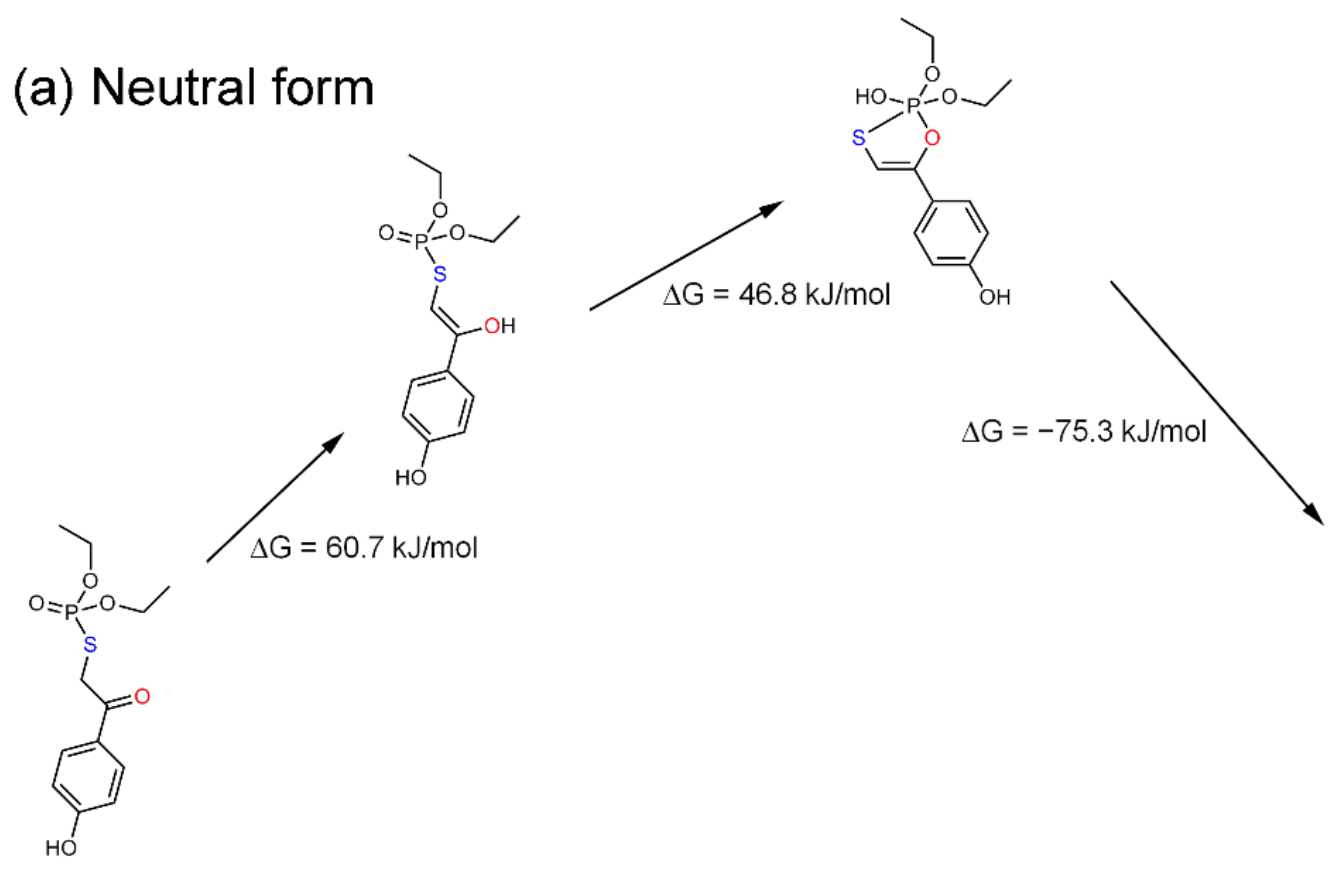

\section{DEPT-OH}

(b) Deprotonated form
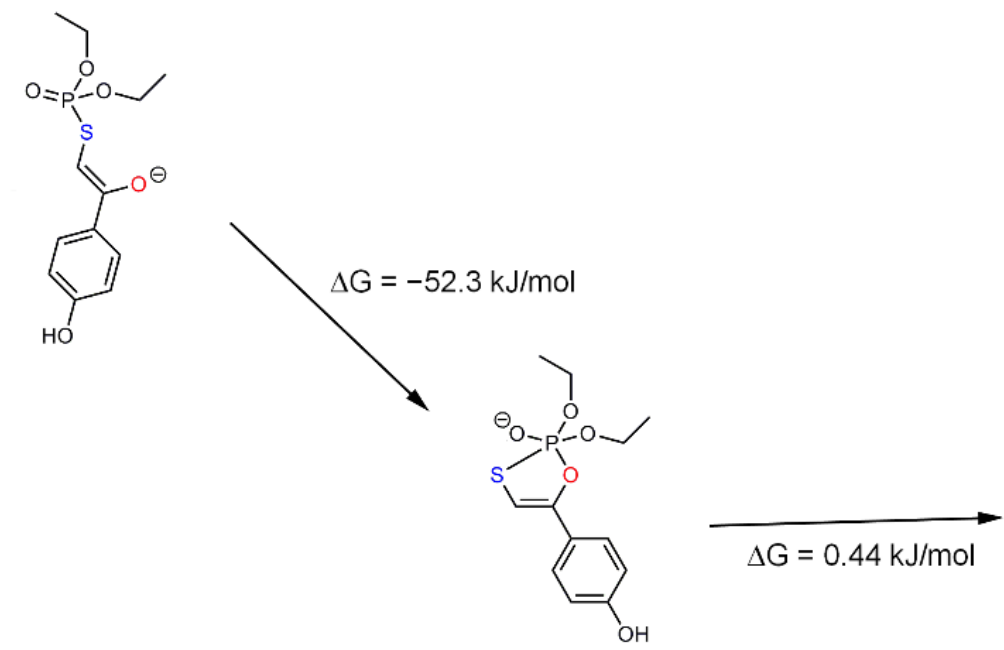

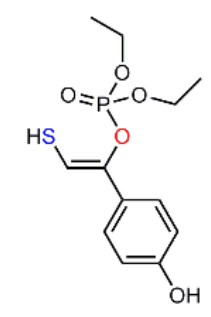

PTET

Figure S6. Gaussian calculation of free energy changes $(\Delta \mathrm{G})$ during the interconversion between DEPT-OH and PTET in their neutral form (a) and deprotonated form (b). The results suggests that the interconversion in the neutral form is difficult (up to $107.5 \mathrm{~kJ} / \mathrm{mol}$ free energy barrier), while that in the deprotonated form is favored for the formation of deprotonated PTET from deprotonated enol form of DEPT-OH $(\Delta \mathrm{G}=-51.9 \mathrm{~kJ} / \mathrm{mol})$. 

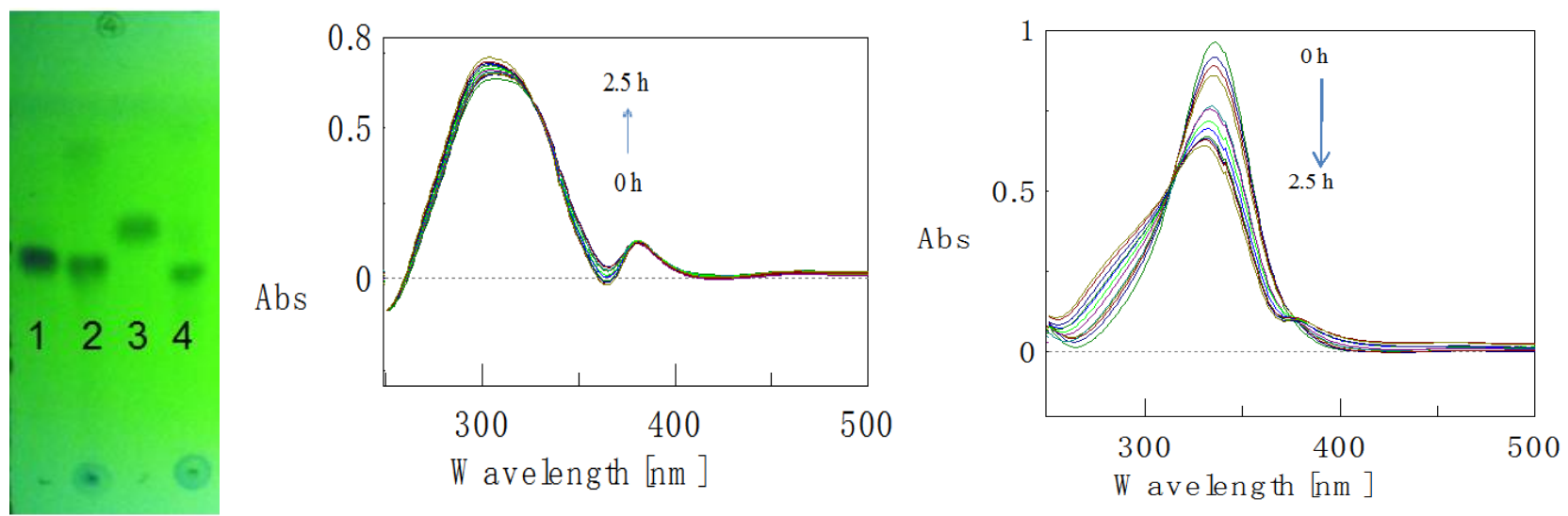

Figure S7. Stability of TEEP-OH and DEPT-OH in 1:1 $\mathrm{CH}_{3} \mathrm{CN} / \mathrm{Buffer}\left(100 \mathrm{mM}, \mathrm{NaHCO}_{3}-\mathrm{Na}_{2} \mathrm{CO}_{3}\right.$, $\mathrm{pH}=10)$ at $40{ }^{\circ} \mathrm{C}$ for $2.5 \mathrm{~h}$. Left: TLC images of TEEP-OH before (1) and after $2.5 \mathrm{~h}$ (2) incubation, and DEPT-OH before (3) and after $2.5 \mathrm{~h}$ (4) incubation. Middle: Changes in UV-Vis spectra for TEEP-OH in $2.5 \mathrm{~h}$. Right: Changes in UV-Vis spectra for DEPT-OH in $2.5 \mathrm{~h}$. The above results suggest TEEP-OH is much more stable than DEPT-OH under basic $\mathrm{pH}$ and elevated temperature conditions.

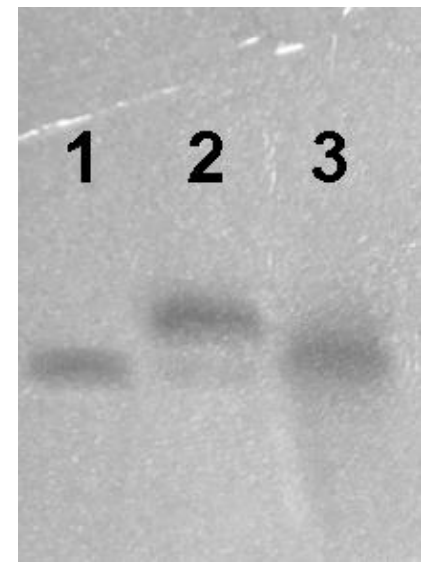

Figure S8a. Image of 20\% denatured PAGE showing the modification and removal of TEEP-OH from a $\mathrm{T}_{15}$ DNA containing 1 phosphorothioate (T15-1PS). Lane 1: T15-1PS; Lane 2: T15-1PS-TEEP; Lane 3: T15-1PS-TEEP+UV. Concentration of DNA is $20 \mu \mathrm{M}$ in 8-17 DNAzyme buffer without $\mathrm{Zn}^{2+}$, and the UV irradiation is $20 \mathrm{~min}$. 

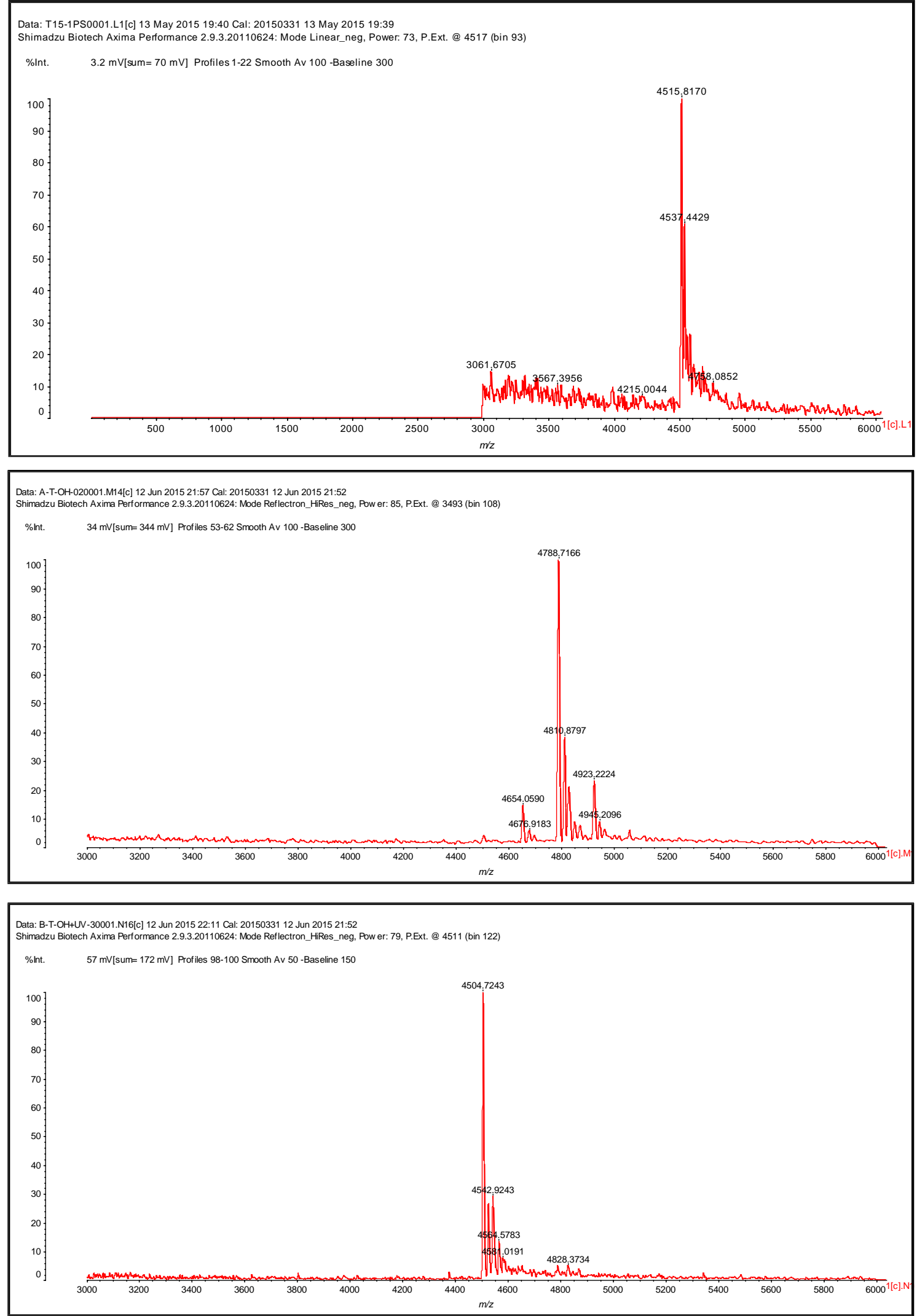

Figure S8b. MALDI-TOF (negative ion) spectra of $20 \mu \mathrm{M}$ phosphorothioate $\mathrm{T}_{15}$ DNA (top, T15-1PS, calc. 4517, found. 4516) with TEEP-OH modification before (middle, T15-1PS-TEEP, calc. 4786, found. 4789) and after (bottom, T15-1PS-TEEP+UV, calc. $4511\left(\mathrm{~T}_{15}\right)$, found. 4505) UV irradiation for 20 min in 8-17 DNAzyme buffer without $\mathrm{Zn}^{2+}$. 

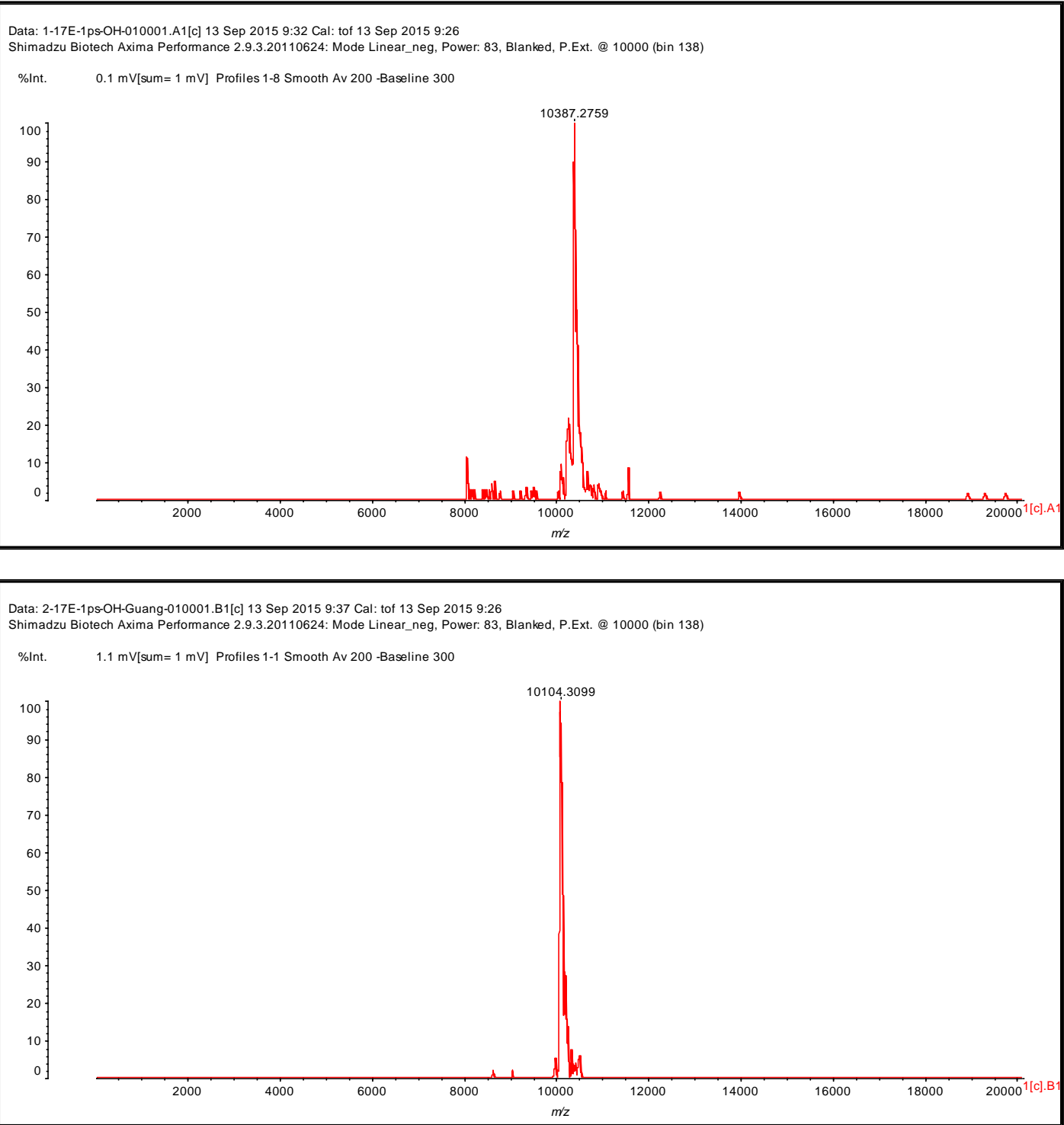

Figure S9. MALDI-TOF (negative ion) spectra of $20 \mu \mathrm{M}$ 8-17-1PS DNAzyme with TEEP-OH modification before (top, 8-17-1PS-TEEP, calc. 10389, found. 10387) and after (bottom, 8-17-1PS-TEEP+UV, calc. 10104 (8-17), found. 10104) UV irradiation for $20 \mathrm{~min}$ in 8-17 DNAzyme buffer without $\mathrm{Zn}^{2+}$. 

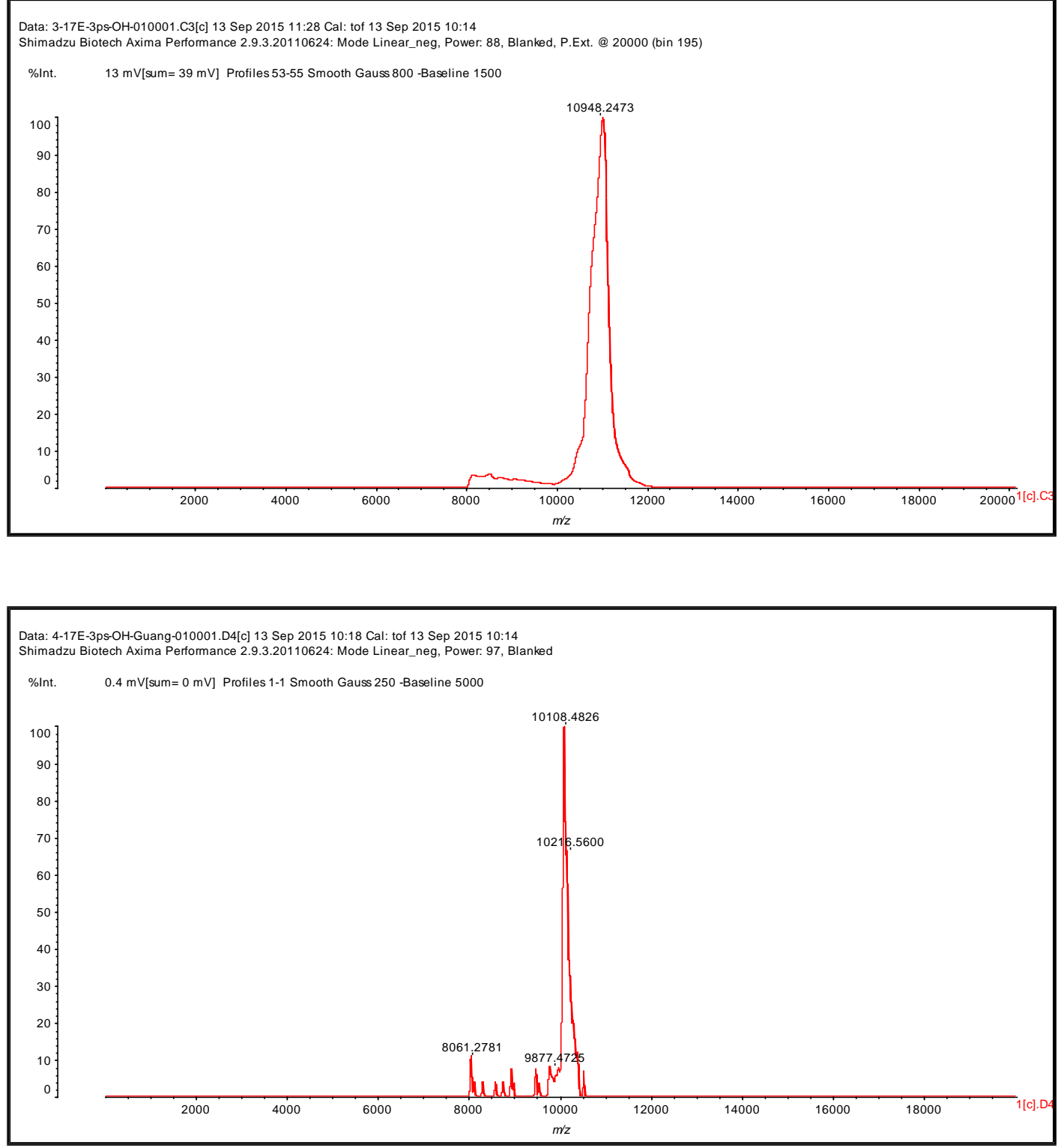

Figure S10. MALDI-TOF (negative ion) spectra of $20 \mu \mathrm{M}$ 8-17-3PS DNAzyme with TEEP-OH modification before (top, 8-17-3PS-TEEP, calc. 10960, found. 10948) and after (bottom, 8-17-3PS-TEEP+UV, calc. 10104 (8-17), found. 10108) UV irradiation for $20 \mathrm{~min}$ in 8-17 DNAzyme buffer without $\mathrm{Zn}^{2+}$. The peak in the spectrum of 3PS-TEEP modified DNA is broader compared with 1PS-TEEP, likely because the ionization is of lower efficiency or the multiple modifications are more vulnerable to MALDI matrix. 

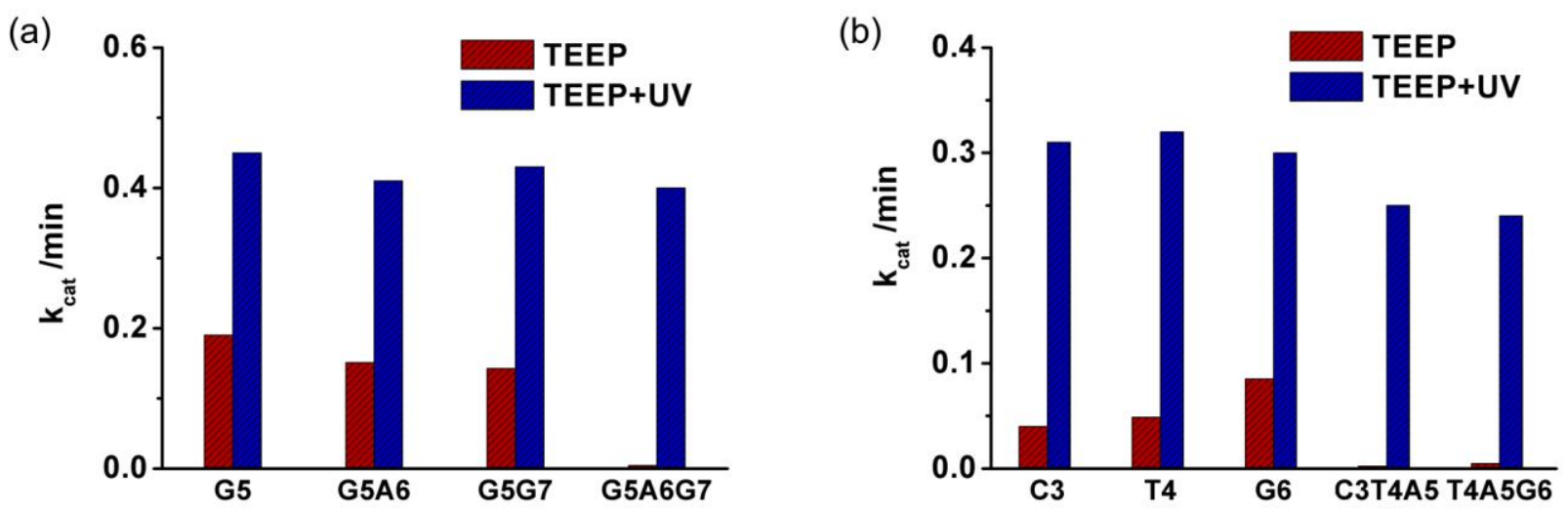

Figure S11. The apparent rate constants $\left(k_{c a t}\right)$ of 8-17 (left) and 10-23 (right) DNAzymes containing different combinations of phosphorothioates in the presence of TEEP-OH modifications before and after UV light irradiation.

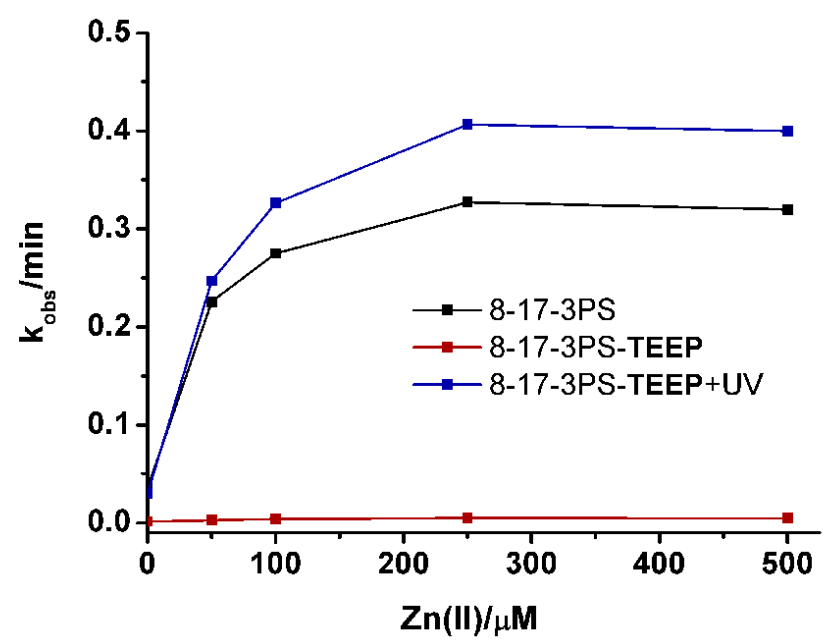

Figure S12. The effect of cofactor $\left(\mathrm{Zn}^{2+}\right)$ concentration on the activity of 8-17-3PS DNAzyme, 8-17-3PS DNAzyme-TEEP and 8-17-3PS DNAzyme-TEEP+UV. 

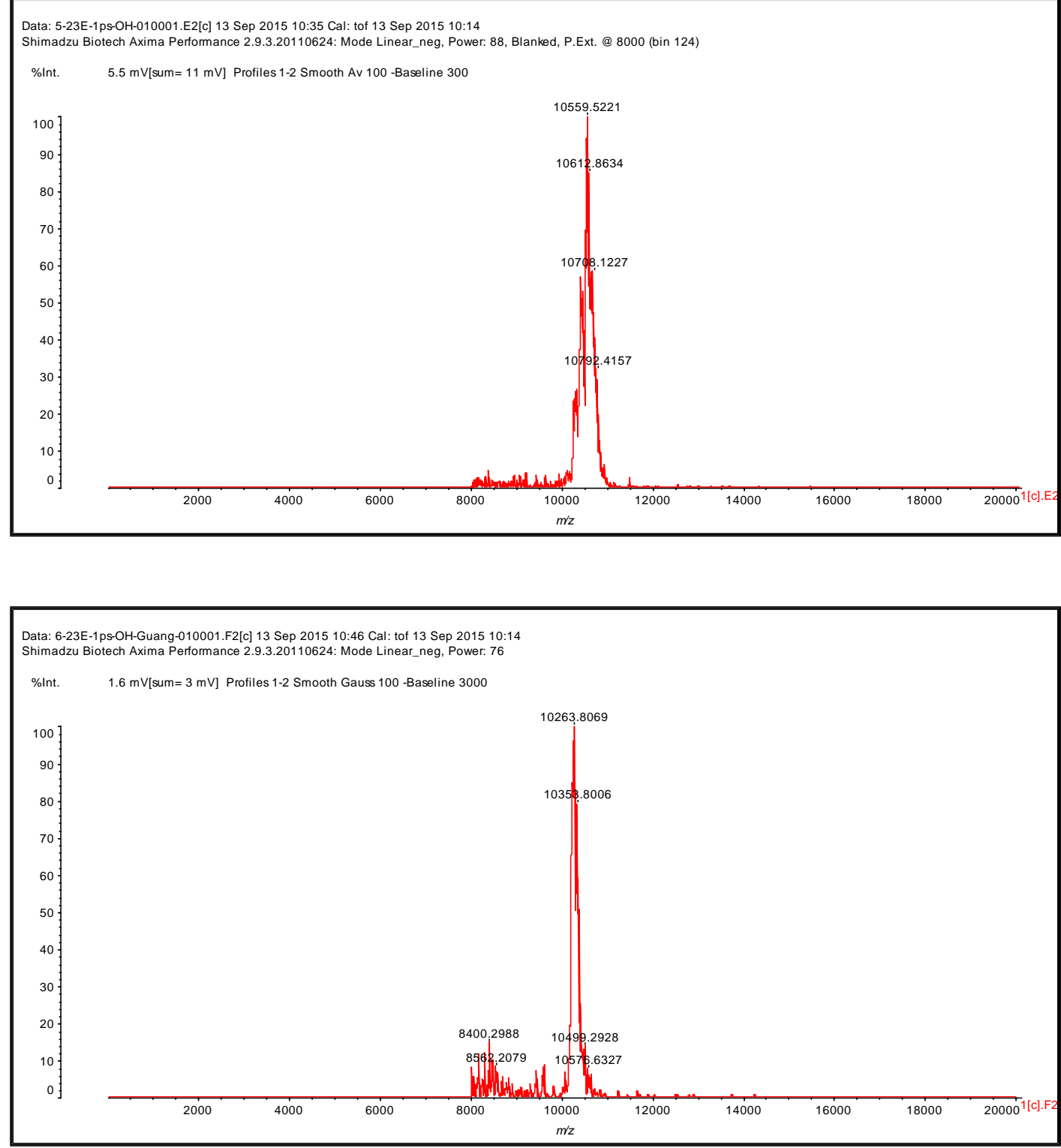

Figure S13. MALDI-TOF (negative ion) spectra of $20 \mu \mathrm{M}$ 10-23-1PS DNAzyme with TEEP-OH modification before (top, 10-23-1PS-TEEP, calc. 10554, found. 10559) and after (bottom, 10-23-1PS-TEEP+UV, calc. 10269 (10-23), found. 10264) UV irradiation for 20 min in 10-23 DNAzyme buffer without $\mathrm{Zn}^{2+}$. 

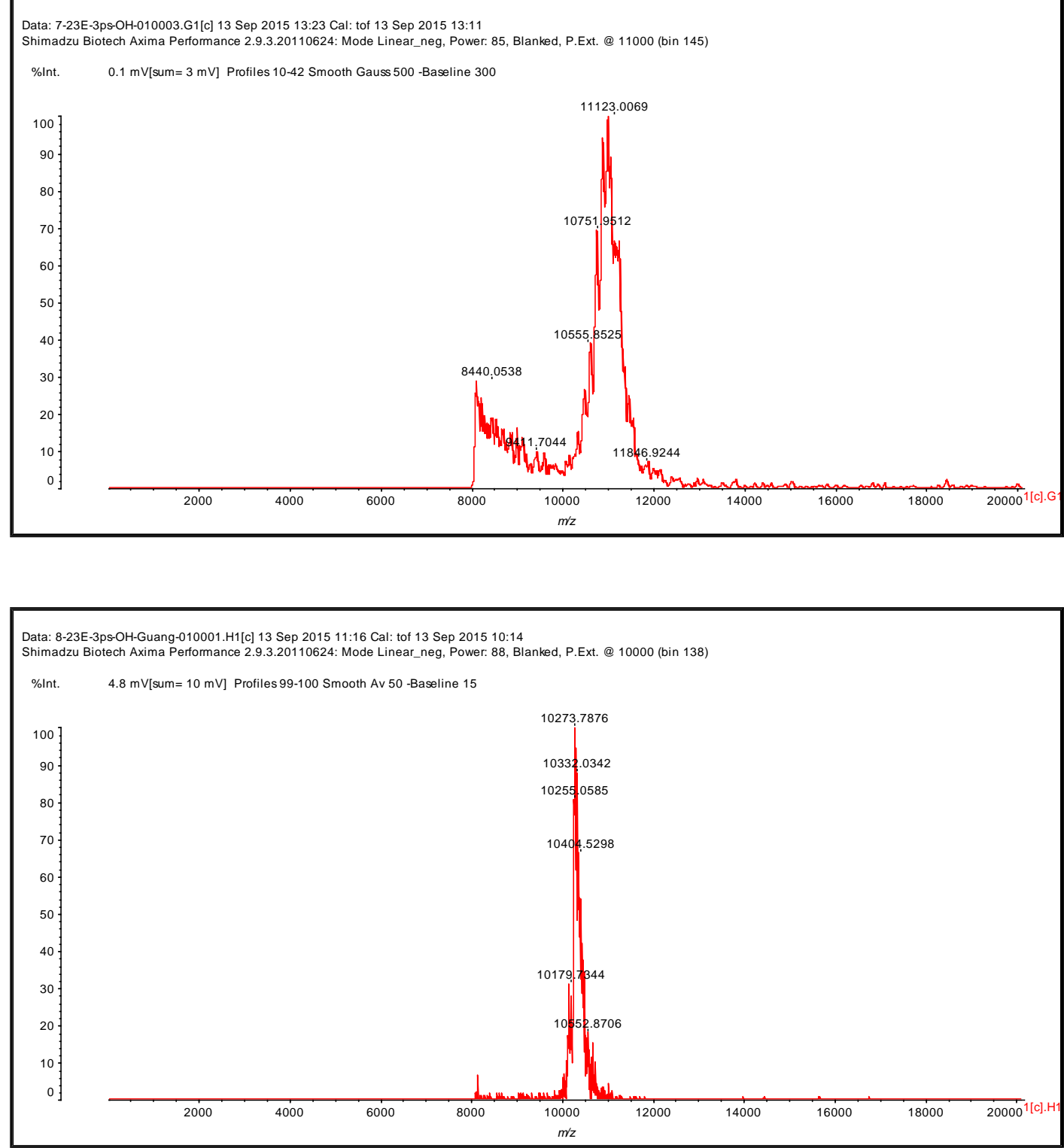

Figure S14. MALDI-TOF (negative ion) spectra of $20 \mu \mathrm{M}$ 10-23-3PS DNAzyme with TEEP-OH modification before (top, 10-23-3PS-TEEP, calc. 11124, found. 11123) and after (bottom, 10-23-3PS-TEEP+UV, calc. 10269 (10-23), found. 10273) UV irradiation for 20 min in 10-23 DNAzyme buffer without $\mathrm{Zn}^{2+}$. The peak in the spectrum of 3PS-TEEP modified DNA is broader compared with 1PS-TEEP, likely because the ionization is of lower efficiency or the multiple modifications are more vulnerable to MALDI matrix. 


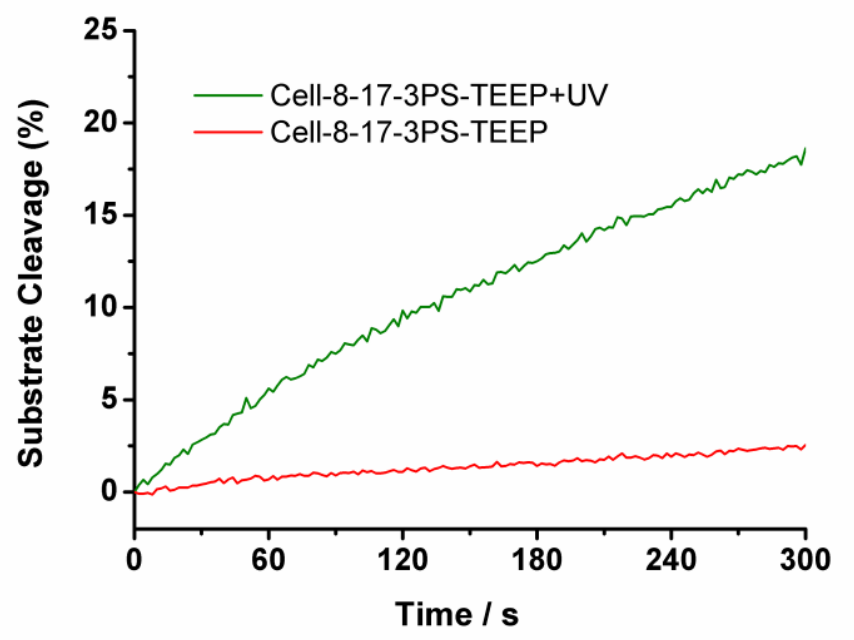

Figure S15. Activation of $1 \mu \mathrm{M}$ 8-17 DNAzyme with 3 TEEP-OH modifications and dual labels by UV light to cleave $500 \mathrm{nM}$ "F-8-17-Q substrate long" in HeLa cell lysates (20-fold dilution in 8-17 DNAzyme buffer to make the lysates transparent for fluorescence measurement). 


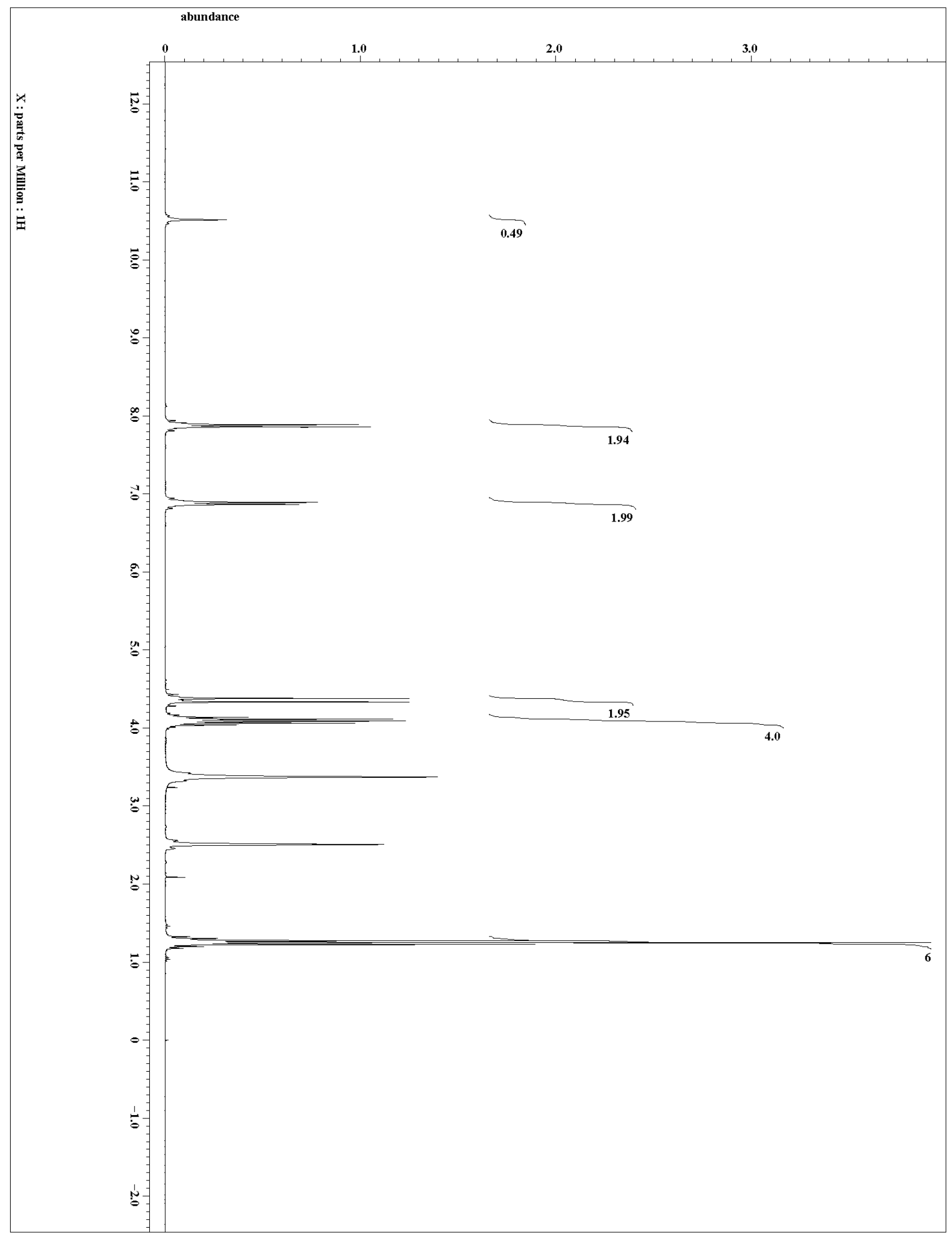

Figure S14a. ${ }^{1} \mathrm{H}-\mathrm{NMR}$ spectrum $\left(\mathrm{DMSO}-\mathrm{d}_{6}\right)$ of DEPT-OH. 


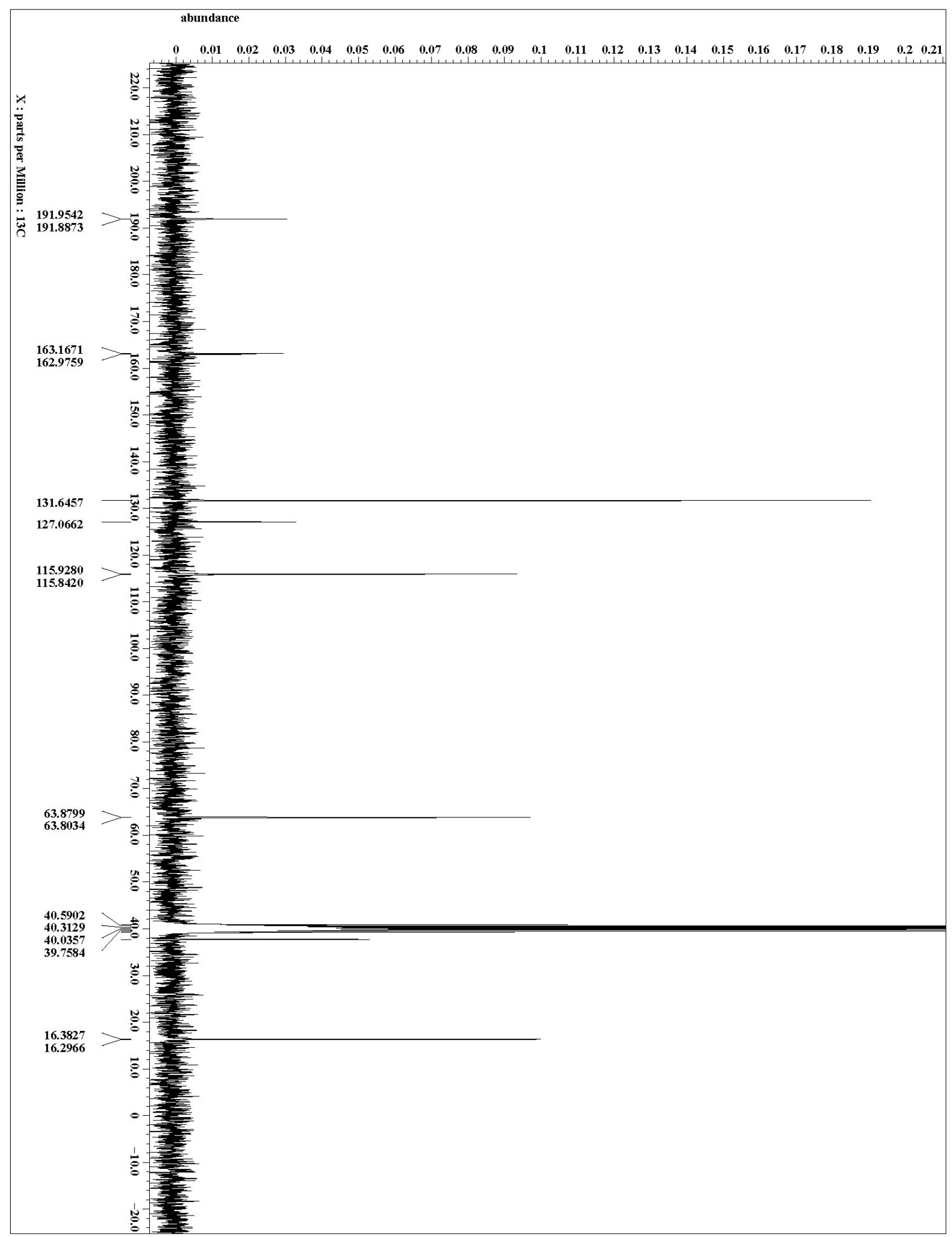

Figure S14b. ${ }^{13} \mathrm{C}-\mathrm{NMR}$ spectrum (DMSO-d 6 ) of DEPT-OH. 


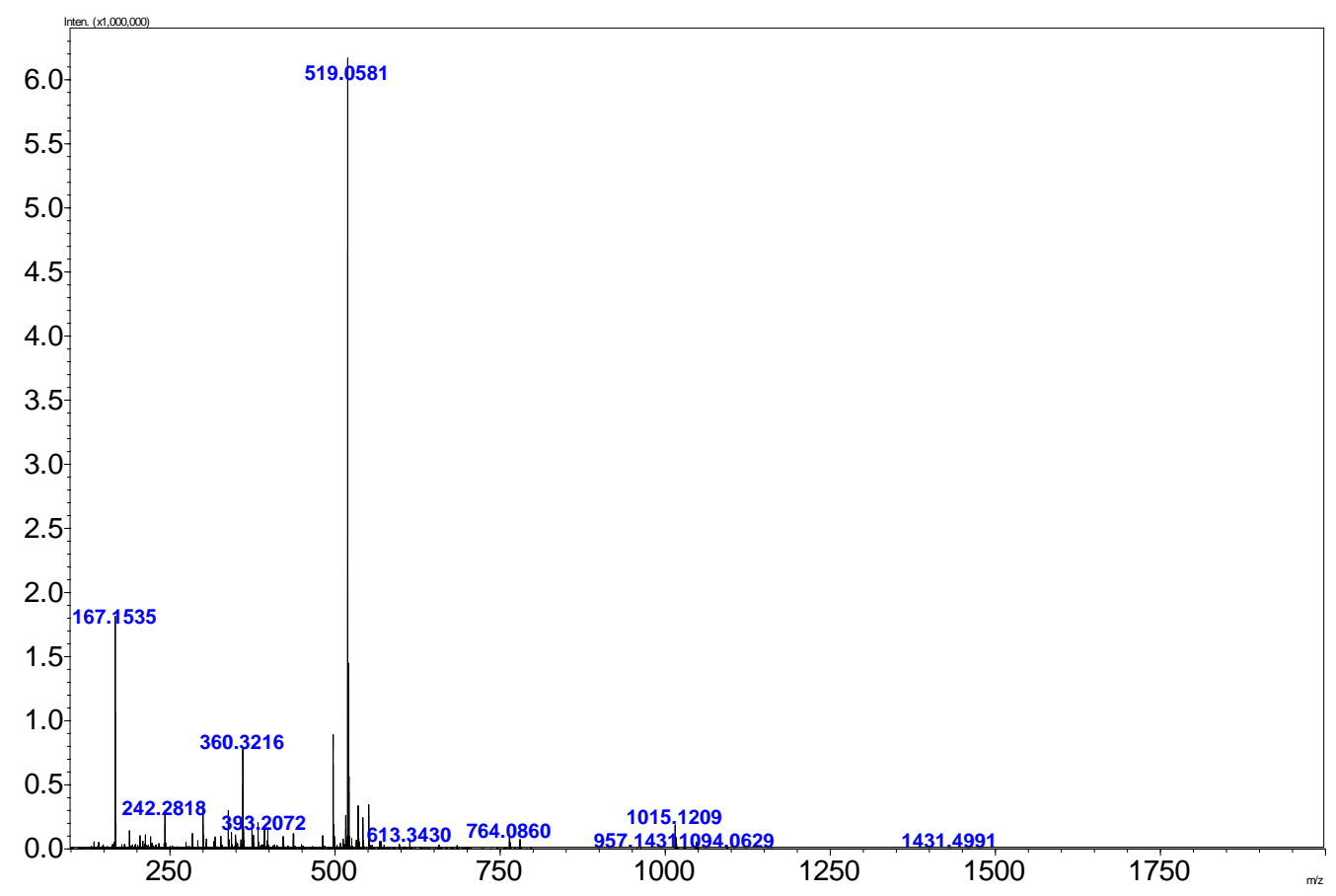

Figure 15a. ESI-MS $\left([\mathrm{M}+\mathrm{Na}]^{+}=519.1\right)$ spectrum of TEEP-NO $2($ calc. $\mathrm{M}=496.4)$. 


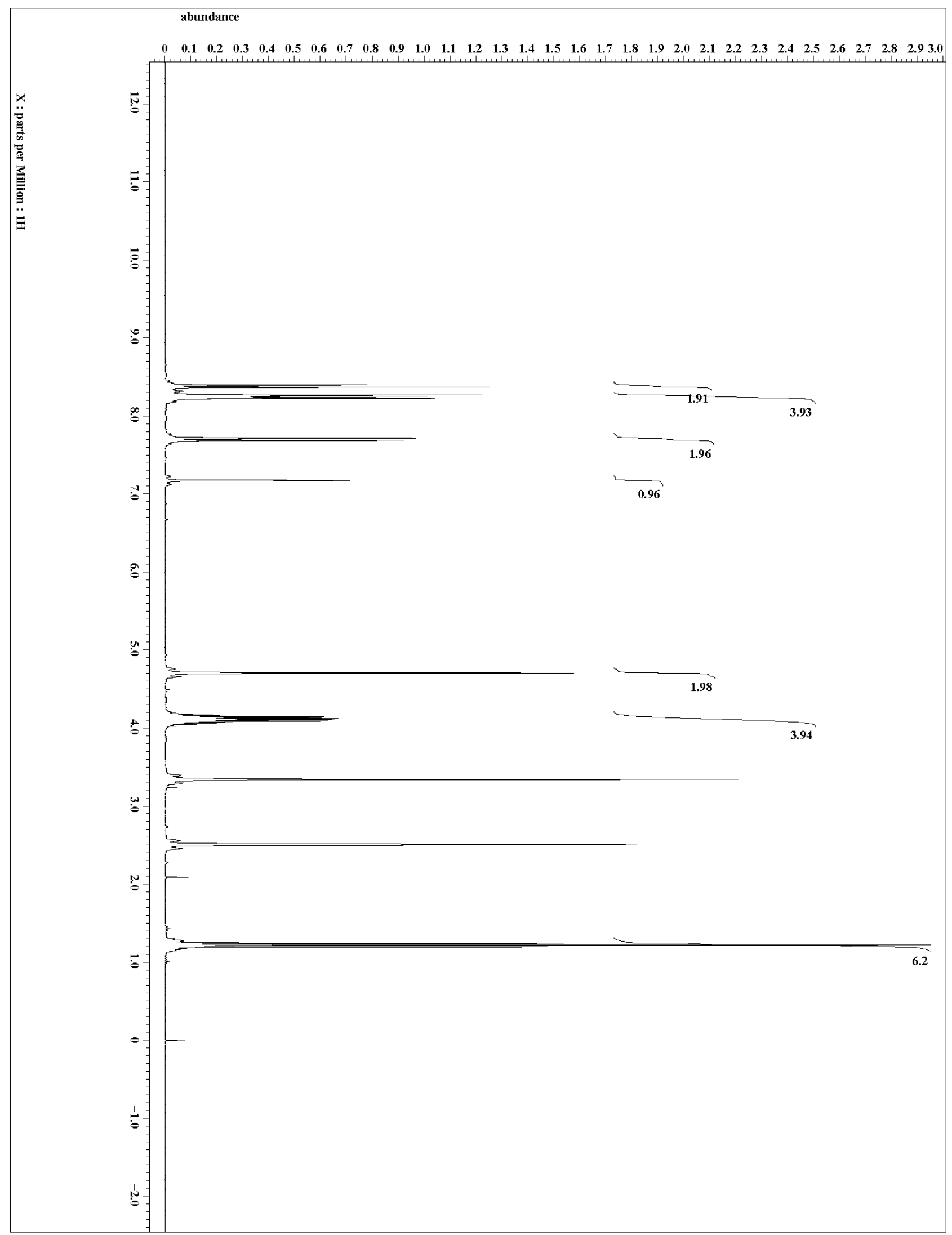

Figure S15b. ${ }^{1} \mathrm{H}-\mathrm{NMR}$ spectrum $\left(\mathrm{DMSO}-\mathrm{d}_{6}\right)$ of $\mathbf{T E E P}-\mathrm{NO}_{2}$. 


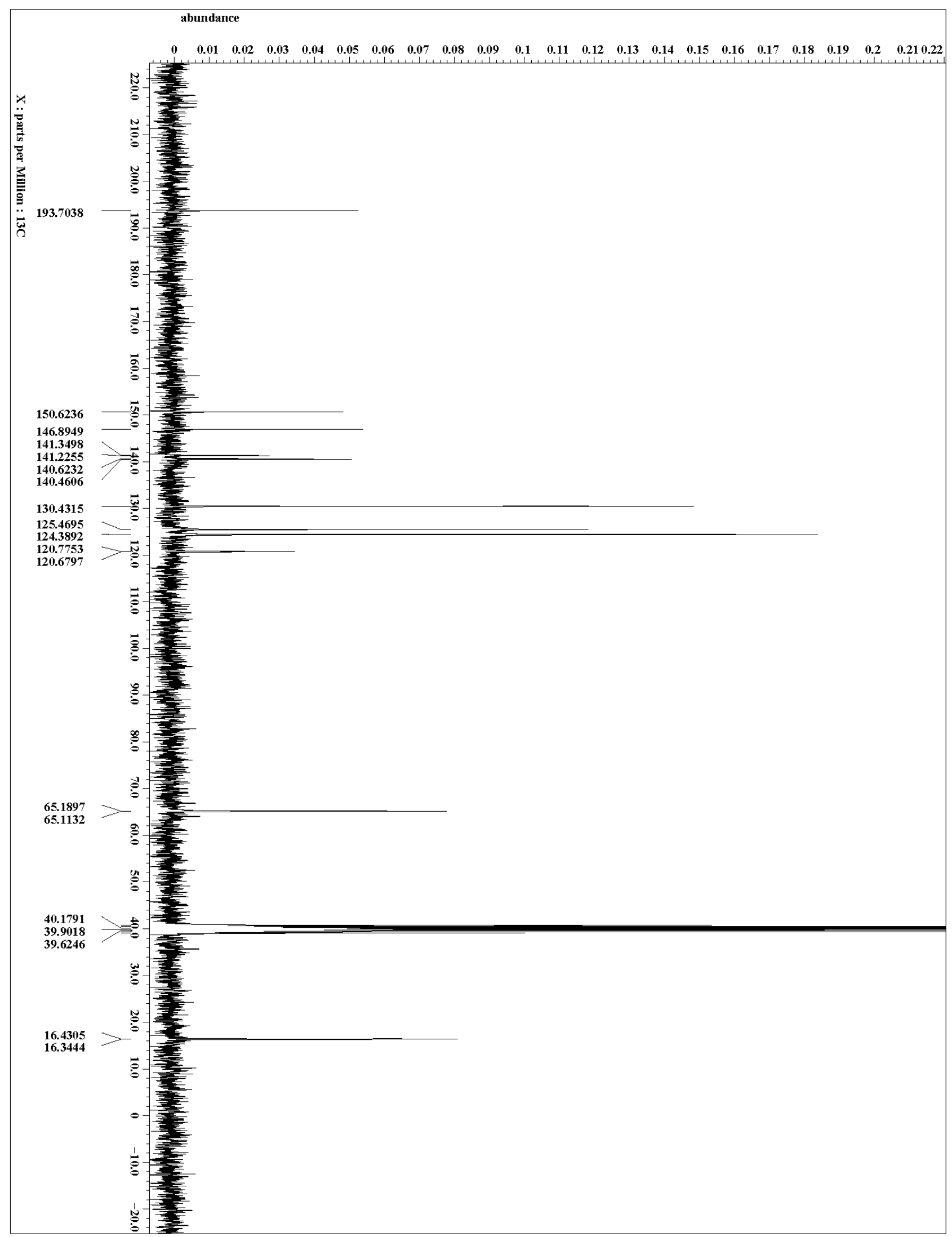

Figure S15c. ${ }^{13} \mathrm{C}-\mathrm{NMR}$ spectrum (DMSO-d $\left.{ }_{6}\right)$ of TEEP-NO ${ }_{2}$. 